\title{
LA CLONACIÓN HUMANA EN LA LEGISLACIÓN INTERNACIONAL: UN ANÁLISIS DESDE LA LINGÜÍSTICA SISTÉMICO-FUNCIONAL
}

\author{
HUMAN CLONING IN THE INTERNATIONAL LEGISLATION: \\ A SYSTEMIC-FUNCTIONAL LINGUISTIC ANALYSIS
}

\author{
Santiago Gabriel Calise \\ Instituto de Investigaciones Gino Germani (IIGG) \\ Consejo Nacional de Investigaciones Científicas y Tecnológicas (Conicet) \\ Universidad de Buenos Aires (UBA) \\ Email: c_santiago_g2000@yahoo.com.ar
}

Recibido: $14 / 10 / 2015$

Aceptado: 16/05/2016

\begin{abstract}
Resumen
El siguiente trabajo se propone analizar la legislación sobre la clonación humana en algunos países en sus diferentes variantes. El objetivo no será examinar el mero contenido de los textos desde el punto de sus argumentos bioéticos, filosóficos o sociológicos, sino que se propone un análisis lingüístico a la luz de la lingüística sistémico-funcional desarrollada por Halliday. En este sentido, se tomarán bajo examen algunos de los componentes que conforman los tres niveles de significación que presenta un texto: los significados experienciales, los interpersonales y los textuales. A través de este abordaje se pretende iluminar la relación entre las selecciones semánticas y las léxico-gramaticales, particularmente obviadas en el debate de estas temáticas. Por medio de estos procedimientos, finalmente, se buscará reinterpretar la función social que cumplen estos textos.

PALABRAS CLAVE: Nominalización; Procesos; Halliday; Gramática sistémico-funcional; Legislación simbólica.
\end{abstract}

\begin{abstract}
The following paper intends to analyze the legislation on human cloning of some countries, who tried to regulate it in its different variants. The aim will not be to examine the very content of the texts from the point of view of its bioethical, philosophical or sociological arguments, but it intends a linguistic analysis in the light of Halliday's systemic-functional linguistics. In this sense, we will examine some of the components, which shape the three levels of meaning of a text: the experiential meanings, the interpersonal meanings and the textual meanings. Through this approach we try to illuminate the relationship between semantic and lexico-grammatical selections, particularly avoided in the debate about this topic. By means of these procedures, we will finally look for a reinterpretation of the social function of these texts.
\end{abstract}

KEYWORDS: Nominalization; Process; Halliday; Systemic-Functional Grammar; Symbolic Legislation.

Para citar este artículo / To cite this article: Calise, Santiago Gabriel (2016). La clonación humana en la legislación internacional: un análisis desde la lingüística sistémico-funcional. ELUA, 30: 9-41. doi: 10.14198/ELUA2016.30.01

Enlace / Link: http://dx.doi.org/10.14198/ELUA2016.30.01 


\section{Introducción}

El presente trabajo analiza la legislación de ocho países diferentes (Alemania, Argentina, Brasil, Chile, España, Francia, Reino Unido, Sudáfrica) en un arco de tiempo que va de 1991 a 2008. Siguiendo el modelo de análisis utilizado en un artículo anteriormente publicado en esta misma revista (Calise, 2014), aquí se propone dejar el contexto argentino, para observar los caminos legislativos que otros países del mundo han tomado. Lo que se propone aquí es analizar estos textos desde la lingüística sistémico-funcional, examinando las tres vetas de significado que constituyen a un texto: los significados experienciales, los interpersonales y los textuales. A su vez, estos significados se corresponderán con las tres metafunciones, en el nivel semántico-discursivo: la función ideacional, la interpersonal y la textual. Para el análisis de cada una de estas metafunciones se tomarán algunos elementos significativos, de manera que para el análisis de la primera se revelará particularmente interesante el trabajo con la diferenciación de los distintos tipos de procesos y de sujetos empleados. En este punto, también resultará sumamente relevante el trabajo con las nominalizaciones. Para el análisis de la metafunción interpersonal el foco de atención se correrá hacia las modalizaciones y las modulaciones. Estas últimas resultan de suma importancia, ya que aquí se trata de textos legales que deben expresar una orden. Lo interesante será ver cómo es que ésta termina siendo expresada. Por otra parte, el análisis de las modalizaciones mostrará el grado de certeza que exhibe el autor del texto al sostener sus dichos, cuestión que se manifiesta muy relevante en relación con una temática que continúa generando fuertes polémicas y posiciones encontradas. Por último, para dar cuenta de la metafunción textual se utilizará la distinción entre tema y rema, para poder observar cómo es que se organiza la información en el nivel donde la cláusula es interpretada en cuanto expresión de un mensaje.

Respecto de la muestra, ella ha quedado conformada por la legislación de ocho países. Naturalmente, esta muestra no puede aspirar a ningún grado de representatividad, sino lo que se ha buscado con ella es incorporar la mayor diversidad posible de posturas, dentro de los idiomas conocidos por el autor, pero que, al mismo tiempo se incluya la legislación de vanguardia, se observe diversidad entre las posiciones y que se privilegie también la situación de América Latina. Pese a que podría parecer más apropiado delimitar el análisis a las lenguas con un mismo origen (romances o germánicas), lo que se busca aquí es poder observar comparativamente las distintas estrategias lingüísticas asumidas con el fin legislar un problema tan sensible y esquivo como es la clonación humana. Por ejemplo, como se verá más adelante, la legislación sudafricana tiene, en muchos aspectos, más puntos de contacto con la legislación del resto de los países que con la británica, aunque compartan el mismo idioma.

Reconstruyendo brevemente el estado de los estudios lingüísticos referidos a los nuevos desarrollos de la biología, uno de los campos más prósperos es el del trabajo con metáforas. Sobre todo, pero no exclusivamente, con el Proyecto Genoma Humano, el código genético ha comenzado a ser entendido metafóricamente como un libro, o, más bien, como el libro de la vida (Ceccarelli, 2004; Hellstein, 2005; Liakopoulos, 2002; Nerlich, Dingwall y Clarke, 2002; Pramling y Säljö, 2007; Prior, 2007; Temmerman, 2007). Este libro está escrito con 4 letras (las bases), que forman palabras y párrafos, los cuales deben ser descifrados, ya que esta escritura se asemejaría a un código. Esta clásica metáfora se ha vuelto una catacresis, ya que ha sido completamente asimilada al discurso científico (Knudsen, 2005). Sin embargo, respecto de la metáfora del libro, Prior (2007) nota que éste, para el científico, no es algo que 
se presente como un objeto a la espera de ser leído o descifrado. Por otro lado, la metáfora del libro de la vida conlleva cierta connotación religiosa, que estaría indicando que este libro estaría escrito en el lenguaje de Dios, y de poder manejarlo se adquiriría un infinito poder (Ceccarelli, 2004; Nerlich, Dingwall y Clarke, 2002).

Otra forma metafórica recurrente en la popularización de estos temas es la de humanizar a los genes dotándolos de capacidad de actuación y motivación (Liakopoulos, 2002; Pramling y Säljö, 2007), situación que también ocurre, por ejemplo, con las células cancerígenas (Williams Camus, 2009). No obstante, este tipo de metáfora no es únicamente patrimonio del discurso lego, sino que también algunos científicos lo han usado a la hora de explicar ciertos fenómenos evolutivos (Journet, 2005).

Además de la metáfora del libro, en los discursos legos sobre genética ha aparecido muy frecuentemente la figura del código genético como plano (blueprint) o mapa (Ceccarelli, 2004; Condit, 1999; Condit y Condit, 2001; Pramling y Säljö, 2007; Ratto, 2006). Ceccarelli señala cómo estas dos imágenes son contradictorias entre sí, puesto que implican una forma diferente de ver la causalidad. Por un lado, un cambio en el plano implica una variación en el producto que se realizará, mientras que un cambio en el mapa se produce como respuesta a una transformación en el territorio. Por consiguiente, concluye la autora, la forma de entender el genoma se presenta tanto de una manera determinista, como optimísticamente abierta a la manipulación humana. Respecto de la metáfora del "blueprint", los trabajos de Condit resultan altamente interesantes para romper con ciertos prejuicios avanzados por algunos críticos del uso metafórico en la popularización del tema del genoma humano. En uno de ellos (Condit, 1999), la autora muestra como la antigua metáfora de la "lotería genética", representante del discurso del "hereditarismo voluntario", tiende a generar mayores reacciones discriminatorias que el discurso de la genética médica — relacionado con la metáfora del plano. Mientras que respecto del grado de determinismo que ambos discursos suscitan, no se detectaron diferencias fundamentales. A su vez, en otro estudio (Condit y Condit, 2001), las críticas van dirigidas contra los trabajos que señalaban que debería sustituirse la metáfora del plano por la de la receta de cocina, ya que ésta permitiría a la gente ver a los genes de una manera más compleja, al provenir de un contexto más familiar, humano y femenino. No obstante, las autoras señalan que esta metáfora sigue simplificando demasiado las cosas, mientras que son falaces supuestos como la oposición entre plano como algo comercial y receta como no-comercial. Por otra parte, la preferencia por una de las metáforas debería estar dictada por el rol que se le quiera dar a la información y tecnología genéticas, y no por el grado de confort que ésta pueda generar o por ciertas connotaciones de género que pueda suscitar. Por último, Nerlich (2009) ha advertido sobre el rol centralmente retórico que tienen las metáforas, en relación con nuevos descubrimientos científicos o meras promesas científicas. En este sentido, un discurso apocalíptico puede servir para atraer atención y financiamiento, aunque también puede hacer emerger miedos que terminen ahogando toda posibilidad de un cambio de comportamiento.

Otros trabajos sobre temas de genética, como el de Calsamiglia y Van Dijk (2004), han buscado analizar la forma en que el tema del genoma humano es vulgarizado, a través del estudio del diario El País de España. La atención, en este artículo, se centra en las explicaciones, descripciones, reformulaciones y metáforas, necesarios en la popularización de un tema científico tan alejado de la visión del mundo del lego. En otro trabajo sobre la prensa escrita y la televisión realizado por Williams, Kitzinger y Henderson (2003), se analiza cómo la imagen 
del embrión es construida social, cultural y políticamente. Por un lado, las autoras destacan como la prensa construye el debate sobre las células madre oponiendo, por una parte, a científicos, políticos laboristas y pacientes, y, por la otra, a los voceros religiosos. Otro estudio de gran relevancia, realizado en el Reino Unido por la socióloga Sarah Parry (2003), analiza los debates parlamentarios y sus estrategias retóricas sobre las leyes relacionadas con el uso de células madre y embriones. Aquí se reconstruyen las posiciones asumidas por los bandos favorables u opositores, los argumentos y los discursos utilizados para justificar esas posiciones. Pero el estudio de los debates parlamentarios sobre el problema del embrión en el Reino Unido, tiene como máxima referencia a los trabajos de Michael Mulkay (1993; 1994a; 1994b; 1995a; 1995b), donde se observan las estrategias retóricas de los grupos favorables y contrarios a la utilización de embriones para experimentación científica. El debate llegó a plantearse, por parte de los partidarios de la ciencia, en términos de la ciencia contra la religión, la fe o creencia contra la razón, la acrítica repetición de dogmas contra la apreciación de una mente abierta, etc. (1995a) No obstante, señala el sociólogo, ambas posiciones fueron claramente dogmáticas y ninguna estuvo dispuesta a evaluar cualquier argumento que no fuese compatible con su visión de los hechos. Pero, además, a fin de cuentas, el apoyo a la investigación con embriones se basó, sobre todo, en la fe en la benevolencia de la ciencia.

En relación con el tema de la clonación humana, los estudios lingüísticos son escasos. Uno de ellos (Hellsten, 2000) muestra cómo ciertas metáforas pueden tener un significado diferente, según la forma en que se las utilice. Para aquellos que se encuentran en contra de la clonación, clonar un ser humano es producir una copia barata de alguien, mientras que para quienes tienen una opinión favorable — sobre todo respecto de la clonación terapéutica- los clones serían productos buenos y útiles. De la misma manera se puede entender la metáfora que concibe a la clonación como una producción en masa. Otro estudio sobre las metáforas de la clonación humana es el de Calise (2011), donde se trabaja con más profundidad la utilización de este recurso retórico por parte del sistema jurídico argentino.

En lo concerniente al análisis semántico de la palabra clonación se pueden reseñar dos trabajos. Hunt Lazerson (1982) señalaba cómo la palabra clon comenzaba a reemplazar a la expresión “carbon copy”. En una respuesta a este artículo, Howe (1983) va más allá de este único significado y destaca cómo el vocablo en cuestión es utilizado en varios contextos. Ante todo, suele estar fuertemente ligado a la idea de dictadura y poder total, más específicamente a la experiencia del nazismo. Por otro lado, también está asociado a la idea de "ingeniería artificial" y a algo de menor calidad. Sólo en el contexto deportivo la palabra clon tiene un significado positivo, cuando un periodista asevera que el club al que pertenece un determinado jugador debería clonarlo, debido a sus grandes habilidades. Pero en general, señala el autor, los usos del vocablo indican un cierto cinismo y pesimismo respecto de la ciencia y la tecnología.

Respecto del género que nos ocupará Alcaraz, Hugues y Gómez (2014) distinguen al lenguaje jurídico en tipos o variantes, según su finalidad comunicativa. Estos son: el legislativo o de los textos legales; el juridiccional o de los jueces; el administrativo o de las administraciones públicas; el notarial. Según los autores, cada uno de estos subgéneros tiene características específicas, aunque ellos entienden que el lenguaje de las leyes se ubica por encima de los demás, debido a que marca las pautas que los demás lenguajes deben seguir. Burgos (2000) comparte esta clasificación, mientras que Prieto de Pedro (1991) distingue entre lenguaje legal (en el que se escriben las normas) y el lenguaje de los juristas (que engloba otras subcategorías, como el lenguaje jurisprudencial, el del foro y el administrativo). 
El rasgo común a estos sublenguajes sería que ellos son los lenguajes por los cuales los profesionales del derecho hablan de las normas. Esto significa que en este trabajo el género que abordaremos es el legislativo o de los textos legales.

Haciendo referencia a las características generales del lenguaje jurídico, los expertos en la materia han destacado diferentes propiedades. Algunas de las principales son las siguientes:

- La opacidad del lenguaje (Alcaraz, Hugues, Gómez, 2014).

- El gusto por lo altisonante y lo arcaizante (Alcaraz, Hugues, Gómez, 2014).

- El apego a fórmulas estereotipadas (Alcaraz, Hugues, Gómez, 2014).

- La audacia en la creación de nuevos términos (Alcaraz, Hugues, Gómez, 2014).

- La redundancia expresiva léxica (Alcaraz, Hugues, Gómez, 2014).

- La inclinación hacia la nominalización (Alcaraz, Hugues, Gómez, 2014).

- La continua referencia a lo anterior (González Salgado, 2009).

- Las palabras supuestamente precisas que adquieren significados insospechados (González Salgado, 2009).

- El abuso de la subordinación (González Salgado, 2009).

- La acumulación de sustantivos, adjetivos o verbos, yuxtapuestos o coordinados con $y$ (Santiago Guervós, 2001).

- El uso de derivados adjetivales, que a veces supone un neologismo léxico (Santiago Guervós, 2001).

- El uso del gerundio (Santiago Guervós, 2001).

- La constante reiteración de un mismo elemento (Santiago Guervós, 2001).

- Compleja estructuración sintáctica que da lugar a enormes párrafos o a la articulación de unas oraciones sobre otras (Santiago Guervós, 2001).

El trabajo comenzará con una breve síntesis de los conceptos centrales de la gramática sistémico-funcional, para luego pasar al análisis de las diferentes leyes separadamente. En el parágrafo conclusivo se intentará ir desde el texto al contexto, buscando conjugar los hallazgos presentados hasta ese momento en forma individual.

\section{Marco teórico}

La aproximación sistémica al lenguaje desarrollada por Halliday y su grupo de trabajo se presenta como funcional, ya que las preguntas que plantea acerca del mismo son de naturaleza funcional y porque interpreta el sistema lingüístico funcionalmente (Eggins, 2004). Desde esta perspectiva el lenguaje está estructurado para producir tres clases de significados: ideacionales, interpersonales y textuales. El lenguaje es entendido, en este sentido, como un sistema semiótico, como sistema de codificación convencional organizado como una serie de elecciones. Por su parte, los significados ideacionales serán los que expresen cómo se representa la experiencia en el lenguaje; los interpersonales indican las relaciones con otras personas y las actitudes entre ellas; mientras que los textuales muestran cómo lo que se dice concuerda y está relacionado con lo que se dijo anteriormente y con el contexto circundante.

En relación con esto último, el texto es entendido como cualquier pasaje que forme un todo unificado. Aquello que mantiene tal unidad entre las cláusulas es la textura, que implica la interacción de dos elementos: la coherencia, que hace referencia a la forma en que un grupo de cláusulas o sentencias se relacionan con el contexto extra-textual; y la cohesión, o sea, la manera en que los elementos que componen el texto se encuentran relacionados para 
formar un todo. En cuanto a la primera, se pueden distinguir dos tipos de coherencia: la relacionada con el registro (registerial) y la genérica. Un texto posee coherencia de registro cuando se puede identificar una situación en la cual todas las cláusulas del texto pueden ocurrir, o sea, cuando se puede especificar para el completo grupo de cláusulas el dominio en el cual se está enfocando (su campo), los roles que el escritor o interactuante juega (su tenor), y cuán estrechamente está ligado el lenguaje a la experiencia que se está comentando (su modo). Por otro lado, la coherencia genérica permite reconocer a un cierto texto como un ejemplo de un género particular. Esto ocurre cuando es posible identificar un propósito unificado que motiva el lenguaje, que se muestra como una combinación particular de valores del campo, el tenor y el modo que co-ocurren regularmente y son estabilizados en la cultura como situaciones típicas.

Todo esto significa que el análisis funcional sugiere que cada dimensión del contexto social está relacionada de manera sistemática e impredecible con cada tipo de significado, de modo que el lenguaje se encuentra relacionado naturalmente con la estructura de la vida social. Las consecuencias de esta aseveración son que, por un lado, si los géneros son formas diferentes de usar el lenguaje se encontrará que los hablantes realizan diferentes elecciones léxico-gramaticales de acuerdo con los propósitos que desean conseguir. Por lo tanto, los textos pertenecientes a géneros disímiles mostrarán diferentes selecciones léxico-gramaticales. Por otro lado, si cada género se constituye por cierto número de diversos niveles relacionados funcionalmente, los diferentes elementos de la estructura esquemática revelará diferentes elecciones léxico-gramaticales. En este contexto, por estructura esquemática se entiende la organización por niveles de los géneros, lo cual significa que no es posible expresar todos los sentidos de manera directa y de una sola vez (Eggins, 2004; Halliday y Matthiessen, 2004, Eggins y Martin, 1997).

En cuanto al registro, cabe especificar el significado de las tres variables antes mencionadas. El campo (field) hace referencia al uso del lenguaje para dar expresión a determinado contenido. Ella varía a lo largo de una dimensión de tecnicidad, que va de lo técnico a lo de sentido común, y está asociada con la realización de los significados ideacionales, que, al mismo tiempo, son expresados a través de los patrones gramaticales de la transitividad y los complejos clausales (clause complex). La variable del modo (mode) está relacionada con el rol que el lenguaje juega en la interacción, e implica dos continuos simultáneos que describen dos tipos diversos de distancia en la relación entre leguaje y situación. Una de ellas es la distancia espacial-interpersonal y la otra es la experiencial. Esta variable resultará de suma importancia en el trabajo, ya que en ella puede ubicarse la nominalización como recurso gramatical. Sin entrar en una descripción profunda de ella, la nominalización provee de dos ventajas: por un lado, al nominalizarse las acciones y las relaciones lógicas, se puede organizar los textos en términos de ideas, razones, causas, etc. Por otro lado, las nominalizaciones aumentan la densidad léxica de las cláusulas, permitiendo empaquetar (pack) más contenido léxico por sentencia. Además, a través de las expansiones del grupo nominal es posible contar, especificar, clasificar, calificar, etc., mientras que con las expansiones del grupo verbal no se puede incluir más contenido del provisto originalmente. También cabe aclarar que las nominalizaciones son entendidas por Halliday (1994; Halliday y Matthiessen, 2004) como metáforas gramaticales, queriendo significar con esto que situaciones donde los significados son típicamente (congruentemente) expresados mediante un patrón lingüístico particular son, en cambio, realizados por otras selecciones lingüísticas menos típicas (incon- 
gruentes). La variable de modo está asociada con la expresión de los significados textuales, que son realizados a través de los patrones gramaticales del tema. La última variable es la del tenor (tenor) que indica las relaciones entre los interactuantes. Ella está dividida en tres continuos: el poder, que señala que los roles puestos en juego pueden ser de igualdad o desigualdad de poder; el contacto, que revela que los roles pueden implicar un contacto más o menos frecuente; y la relación afectiva, que puede ser baja o alta, según cuán emocionalmente involucrados o comprometidos se encuentren los enunciadores en la situación. Esta última variable se encuentra asociada con la realización de los significados interpersonales, que, a su vez, serán expresados a través de los patrones gramaticales del $\operatorname{mood}^{1}$.

Comenzando con la gramática de los significados interpersonales, debe señalarse que cada cláusula, en este plano, puede dividirse en sus respectivos componentes funcionales: el mood (quien lleva adelante el argumento) y el residuo. El mood, a su vez, está compuesto por el sujeto y el finito. Aquí el sujeto es definido como aquel que lleva a cabo la acción en relación con la cual la proposición puede ser afirmada o negada. Por su parte, el finito es aquel que ancla la proposición de manera que se puede discutir sobre ella. Él presenta dos tipos de operadores verbales, uno temporal — que ancla la proposición en relación con el tiempo - y otro modal — que la ancla con referencia a la modalidad, a saber, con elementos que expresan el parecer del hablante en relación con la probabilidad de algo. Por otro lado, el residuo está compuesto por el predicador (la parte léxica o de contenido del grupo verbal) y por los complementos (típicamente un grupo nominal).

El otro componente interpersonal de importancia que será trabajado aquí es el sistema de la modalidad, que se divide en modalización y modulación (Eggins, 2004; Halliday y Matthiessen, 2004). La primera se mueve entre los polos del sí y del no, y es usada para expresar la probabilidad o frecuencia de las proposiciones. Ella puede indicar dos tipos de significados: la probabilidad y la usualidad. Respecto de la modulación, la teoría indica que ella sirve para discutir sobre la obligatoriedad o la inclinación hacia ciertas propuestas. Por otro lado, la modalidad podrá ser expresada de dos maneras: en forma de metáfora gramatical (a través de giros como: "yo creo", "yo supongo", "yo pienso", etc.), de modo que la modalidad es realizada en la cláusula. Aquí la modulación es introducida en el finito, como un operador verbal modulado, pudiendo expresarse de manera subjetiva u objetiva. La otra forma que se expresa la modalidad es por medio de una pseudo-cláusula que funciona como adjunto. En última instancia, todas ellas significan "yo pienso, en mi opinión, que...", aunque también se suelen utilizar fórmulas que oculten al hablante detrás expresiones objetivas.

Pasando al análisis de la metafunción ideacional, cabe aclarar que ella se divide en dos componentes: los significados experienciales y los lógicos. En este trabajo se ha optado por analizar nada más que los primeros, dejando de lado los segundos. Es por ello que aquí solamente se aclararán los conceptos referidos a los significados experienciales, o sea, al sistema de la transitividad. Al observar la metafunción experiencial, aquello que se observa es la gramática de la cláusula en cuanto representación. Este sistema, a su vez, está dividido en dos: uno mayor, constituido por seis tipos de procesos; y uno menor, formado por los circunstanciales. El primer tipo de procesos es el de los materiales, que, semánticamente,

1 Se ha preferido no traducir el término mood, porque las traducciones al español suelen utilizar la palabra "modo", tanto para traducir mood como mode. De esta manera se crean confusiones inútiles e injustificadas (porque "modo" no refleja el significado de mood). Por lo tanto, se ha usado "modo" para traducir a mode, dejando sin traducción a mood. 
se define como una entidad que hace algo. Los participantes en estos procesos pueden ser uno (alguien que hace algo), o dos o más (alguien hace algo y ese hacer involucra otra entidad). Por otra parte, también se distingue entre los participantes directos: el actor, que es el componente de la cláusula que hace la acción; y la meta (goal), que es a quien se dirige el proceso. A su vez, la teoría distingue entre la meta y el alcance (range), el cual sirve para especificar: o es una reafirmación o continuación del proceso mismo; o expresa la extensión del alcance del proceso. Por otra parte, también pueden distinguirse los "beneficiarios", que son de dos tipos: el destinatario, al cual se le da algo; y el cliente, a quien algo les es hecho.

Los procesos mentales, por su parte, no hacen referencia a las acciones o hechos en un sentido físico y tangible, sino a las reacciones mentales que provocan. Se distinguen tres clases de procesos verbales de este tipo: los cognitivos, los afectivos y los perceptivos. Otra característica de los mentales es que siempre implican dos participantes. Uno de ellos debe ser un ser humano consciente (el senser) y el fenómeno, que puede ser un acto o un hecho. Por su parte, los procesos conductuales se encuentran a mitad de camino entre los materiales y los mentales, e implican, típicamente, procesos de conducta fisiológica o psicológica. Mayoritariamente, a diferencia de los mentales, estos involucran un solo participante, aunque, igual que para los anteriores, ellos necesitan de la presencia de un ser consciente (el behaver). Una cuarta categoría la representan los procesos verbales, que, normalmente presentan tres participantes: el sayer, que es el responsable del proceso verbal; el receptor (receiver), a quien es dirigido el proceso verbal; y la "verborragia" (verbiage), o sea, la afirmación nominalizada del proceso verbal —en otras palabras, un nombre que expresa algún tipo de conducta verbal.

Por último, se encuentran dos tipos de procesos bastante emparentados, ya que aquí se pasa de la acción al ser con los existenciales y los relacionales. Los primeros se limitarán a afirmar simplemente que ciertas cosas existen, mientras que los segundos agregarán que esas cosas se encuentran en relación con otras. Los relacionales se distinguirán, a su vez, en varios tipos: los intensivo-atributivos, los intensivo-identificativos, los circunstanciales, los posesivos y los causativos.

La última metafunción que queda por repasar es la textual. Ella designa el nivel de organización de la cláusula que permite que ella sea "empaquetada" (packaged) en formas que la hacen efectiva dados sus propósitos y su contexto. Los sistemas centrales que dan expresión a este tipo de significados son el sistema del tema y el sistema de la estructura de la información (que se realiza a través de las elecciones de entonación). Aquí interesará, sobre todo, el primero de los sistemas, que se concretiza por medio de una estructura por la cual la cláusula es dividida en dos constituyentes principales. El sistema del tema implica en sí tres subsistemas, ya que conlleva la selección de un tipo de tema, la marcación o no-marcación del tema y de tema predicado o no-predicado, que involucra el uso de un elemento clausal adicional. La definición misma del concepto de tema es algo que le ha resultado complicado al mismo Halliday ${ }^{2}$, quien solamente ha podido aportar una definición metafórica del mismo. En la última versión de An Introduction to Functional Grammar, puede leerse: "the Theme is the element which serves as the point of departure of the message; it is that which locates and orients the clause within its context (Halliday \& Matthiessen, 2004: 64). Por el contrario, el rema será definido como la parte de la cláusula en la que se desarrolla el tema.

2 Para un análisis puntual sobre este problema, puede remitirse a Montemayor-Borsinger 2009, 2011. 
Pasando al análisis más detallado del concepto de tema, debe notarse que existen tres tipos de elementos de la estructura de la cláusula que pueden asumir la posición del tema: los elementos tópicos o experienciales, los interpersonales y los textuales.

El criterio para identificar el tema es de naturaleza posicional, por lo cual lo que viene primero es el tema y lo que lo sucede constituye el rema. En general, y sobre todo para el inglés, se entiende que el primer elemento o grupo de elementos que cumple una función en la estructura experiencial de la cláusula es el tema. Cuando el tema coincide con el sujeto gramatical, entonces se está frente a un tema tópico no-marcado. En español (MontemayorBorsinger, 2007) el concepto de tema no-marcado debe ampliarse, debido a la existencia del sujeto tácito. Por lo tanto, en las declarativas, tanto el sujeto como el verbo conjugado y los clíticos pueden ocupar la posición de tema no-marcado. Cuando sujetos y temas coinciden, como dice Montemayor-Borsinger (2007: 136), es porque, por razones funcionales, el emisor decidió fusionar el andamiaje del texto, con los puntos sobre los cuales arguye el mismo. Por el contrario, cuando el tema no se identifica con ninguno de los elementos gramaticales antes mencionados, sino con un complemento o un circunstancial, entonces se está frente a un tema tópico marcado. Algunos de los temas marcados más frecuentes son los circunstanciales de tiempo y de lugar. Esto sirve para otorgar al discurso ciertos puntos de referencia. También, señala la misma autora, al romper la secuencia más frecuente de sujeto-verbo-predicado, el efecto que se puede estar buscando es el de añadirle emotividad al mensaje. Por último, debe agregarse que la teoría afirma que cada cláusula debe tener un solo tema tópico obligatoriamente. Por lo tanto, cada cláusula podrá contar también con un tema interpersonal y/o un tema textual, pero deberá también tener uno tópico.

Por su parte, los temas interpersonales se presentan cuando, al principio de la cláusula, se encuentra un componente que puede ser clasificado como parte del mood, pero forma parte del sistema de transitividad. En español (Ghio y Fernández, 2008: 122) este tipo de temas puede incluir los siguiente elementos: un finito (en las estructuras interrogativas); un pronombre relativo (también en las interrogativas); un vocativo; un adjunto típicamente encarnado por un adverbio, que sirve para comentar, evaluar o expresar la actitud del emisor; o cláusulas mentales de primera y segunda persona que expresan una opinión del emisor o tratan de lograr una opinión del interlocutor.

Por último, los temas textuales tienen la función de cohesionar la cláusula con su contexto textual. Ellos pueden estar marcados, centralmente, por dos tipos de adjuntos: los continuativos (que establece una relación con lo previo [“o sea", "a saber", etc.]) y los conjuntivos (conjunciones que marcan una relación de coordinación; conjuntivos que establecen un lazo cohesivo con lo anteriormente dicho ["además", "luego", etc.]).

\section{La legislación sobre la clonación:}

\subsection{La Embryonenschutzgesetz de Alemania (1991)}

Esta ley, como dice su título, está dirigida a la protección de los embriones, e incluye un apartado dedicado a la clonación ( $(6)$. La ley es altamente sintética y poco detallada, si se la compara con la legislación francesa. Desde el punto de vista textual, el legislador ha preferido la utilización de temas cortos (dos no-marcados y uno marcado), y solamente el artículo primero presenta un rema largo y más complejo. Por su parte, los significados ideacionales muestran 
un menor grado nominalización de los procesos que las leyes de los otros países analizados (el 57\%), aunque, como en los demás casos, prevalecen los significados materiales de manera neta. Estos procesos describen las acciones de los infractores y la correspondiente reacción que le corresponde al sistema jurídico. Lo que más sorprende del lacónico estilo adoptado por el legislador alemán es la clara falta de significados visiblemente relacionados con la clonación y las prácticas ligadas a la misma. En efecto, solamente el título del parágrafo hace referencia a la misma (Klonen), pero luego en los artículos no se consolida un campo semántico en torno de esta práctica, ni se encuentran las palabras que en las otras leyes y proyectos suelen ir de la mano. Si se analizan los sujetos de estos procesos, se encuentra el predominio del sujeto abstracto "quien" (wer), que en la legislación de los otros países tiende a utilizarse lo menos posible. Por último, el examen de los significados interpersonales muestra la ausencia de modalizaciones y la presencia de dos formas de modulación, a través del pasivo ("wird bestraft") o del verbo ser seguido de un adverbio ("ist strafbar") con valor de voz pasiva. Desde el punto de vista semántico, a través de estos tres artículos, queda prohibido todo tipo de práctica que implique la producción de un embrión clonado ${ }^{3}$. El artículo dos, específicamente, castiga la implantación de un embrión clonado en una mujer, aunque no altera las penas indicadas en el primero de los artículos. Al igual que en España, las penas de prisión no superan los cinco años, lo cual muestra la distancia entre las sanciones contempladas por estos dos países y la desproporcionadamente más alta indicada por Francia.

\subsection{Decreto 200/97 de Argentina}

El texto se encuentra dividido en dos secciones, primero los considerandos y luego los artículos. Desde el punto de vista textual, la primera parte está fuertemente ritmada por la permanente presencia de los temas textuales iniciados por el nexo "que", que otorga un fuerte sentido de acumulación a la argumentación, al mismo tiempo que hace parecer completamente lógica a la conclusión a la que se arriba. Por su parte, los artículos presentan todos temas no-marcados con temas y remas cortos.

En el plano ideacional salta a la vista rápidamente la fuerte metaforización de los procesos llevada a cabo sobre todo en los considerandos. De esta manera, el 61\% de los procesos se encuentra metaforizado. En general, prevalecen los procesos materiales, sea entre los metaforizados que entre los no-metaforizados. Esta prevalencia de los materiales expresa, especialmente en los no-metaforizados, las acciones del sistema político que ha realizado o va a realizar, mientras que los procesos metaforizados muestran también esto mismo, aunque se agrega la presencia de las prácticas científicas.

Observando quiénes realizan los mencionados procesos puede apreciarse que, en los considerandos, casi la mitad de los sujetos son instituciones del Estado o el Estado mismo $\mathrm{y}$, en un caso, el presidente en persona, mientras el resto son sujetos abstractos ("los avances científicos"; "la información"; "el decreto", etc.), que en varios casos son procesos metaforizados. En esta parte, todavía se puede observar un actor bien concreto, mientras que en los artículos, de los ocho procesos, en siete ocasiones se ha preferido el "se" para expresar las órdenes provenientes del ejecutivo.

3 Como señala Pattinson (2002), la ley habla de un embrión "genéticamente idéntico", de manera que la transferencia nuclear podría quedar afuera de esta definición, por la diferencia en el ADN mitocondrial. 
Pasando hacia los significados interpersonales puede notarse que el texto en su totalidad recurre muy escasamente a modalizaciones, encontrándose en los considerandos solamente dos: "debe asegurar y garantizar" y "resulta de urgente necesidad". Ambas son objetivas, siguiendo la tendencia claramente impersonal del texto, e indican necesidad. Más importantes son las modulaciones, algunas de ellas presentes en los considerandos, pero más relevantes las de los artículos, ya que ellos expresan únicamente órdenes. La mayoría de estas modulaciones se encuentran en su forma más congruente, el imperativo, mientras que las de los artículos $1^{\circ}$ y $2^{\circ}$ ("prohíbense" y "encomiéndase") se encuentra en el presente del indicativo, como sucede en casi todos los proyectos de ley ${ }^{4}$.

En cuanto a su contenido semántico, el decreto sostiene que, siendo la clonación humana una cuestión que plantea "problemas éticos y morales que se contraponen a las pautas y valores culturales propios de nuestro pueblo", y habiéndose "tomado conocimiento del impacto generado en la comunidad internacional" y de las "opiniones formuladas por representantes de distintos credos religiosos e instituciones científicas y de las decisiones adoptadas por gobiernos de diversos países", se establece: "Artículo $1^{\circ}$-Prohíbense los experimentos de clonación relacionados con seres humanos." Al mismo tiempo, el Poder Ejecutivo comandaba al Ministerio de Salud y Acción Social a elaborar un anteproyecto de ley sobre la temática, para que sea tratado en el Congreso. Pese a los varios proyectos que se fueron presentando ante el Poder Legislativo, ninguno prosperó.

Respecto de esta sanción, la doctrina es bastante crítica, ya que algunos hablan de una decisión “apresurada” (Messina de Estrella Gutiérrez, 1998), llegándose a sostener que la legalidad de tal decreto es "discutible" (Belluscio, 1999). Pero otra interpretación más profunda (Kemelmajer de Carlucci, 2001) indica que este decreto impediría la experimentación de clonación con piel humana, la elaboración de insulina humana o de ciertas vacunas.

Como puede observarse en estos análisis, tal sanción tiene dos claros perjuicios: por un lado, al ser un decreto, no tiene valor de ley penal, por lo tanto, no puede prohibir la práctica de la clonación; mientras que, por otro lado, su mala redacción impediría la realización de otros procedimientos que nada tendrían que ver con la clonación reproductiva, y que parecen no ir en contra de la opinión ética generalizada. Desde el punto de vista del género lingüístico, también puede verificarse la intención explícita del Poder Ejecutivo de "legislar", ya que los artículos se ajustan claramente a las características del derecho penal.

\subsection{La National Health Bill de Sudáfrica (2003)}

Sudáfrica, al igual que, por ejemplo, Brasil, cuenta con una ley que específicamente prohíbe la clonación reproductiva, al tiempo que permite la terapéutica en el artículo 57 de la National Health Bill. Del análisis léxico-gramatical cabe resaltar que entre los procesos no-metaforizados hay una relevante presencia de relacionales y mentales en la última parte del artículo, justamente cuando se dan las definiciones respecto de los dos tipos de clonación indicados. El análisis de los significados interpersonales muestra ciertas particularidades a la hora de expresar las modulaciones. La forma más reiterada utiliza el verbo modal "may" para indicar el permiso ("may not manipulate or engage", "may permit", "may be pres-

4 Ver Calise, 2014. 
cribed", "may import or export") que es una forma altamente metaforizada y modalizada. Ella no solamente oculta al poder que impone la prohibición o las condiciones para poder realizar una clonación terapéutica, sino que también implica una especie de llamada cortés a la obediencia, al tiempo que involucra un cierto grado de improbabilidad. La otra forma, un poco más explícita, se da a través de la voz pasiva o del verbo "ser" seguido de un adjetivo ("is obtained", "is guilty", "is liable") también sirve para ocultar al poder que prescribe la sanción, aunque excluye todo componente modalizador. Puede notarse, además, que esta fórmula está también presente en la ley inglesa.

Desde el punto de vista semántico, esta ley excluye explícitamente la posibilidad de clonar un ser humano en territorio sudafricano, aunque también reglamenta bajo qué condiciones puede utilizarse esta técnica con fines terapéuticos. En este sentido, los investigadores que deseen indagar respecto de alguna patología y encontrar alguna cura mediante el empleo de embriones humanos requerirán del permiso estatal. Aquí también se explicita la doctrina que permite la investigación con embriones de no más de 14 días. En cuanto a las penas, esta ley vuelve a considerar que el castigo máximo imponible no puede superar los cinco años de prisión y una multa cuyos montos no están establecidos. Por último, al igual que en el caso brasileño, el legislador ha optado por incorporar definiciones en el texto, las cuales siempre implican cierto peligro. Uno de ellos es, por ejemplo, el nombrar las técnicas de transferencia nuclear o división de embriones como medios para realizar una clonación terapéutica. Más allá de que el abanico de técnicas hoy disponible es mucho más amplio y complejo, siempre existe el riesgo de que se desarrolle una técnica completamente diferente a estas dos y que no sea subsumible bajo ninguna. Por otro lado, al igual que en el caso brasileño, la definición de clonación terapéutica es claramente redundante y termina por no aclarar realmente en qué consiste tal práctica.

\subsection{Ley 2004-800 de Francia (2004)}

Esta es una ley dedicada a cuestiones bioéticas y es una de las que tratan el problema de la clonación humana de manera más abarcadora. Debido a su extensión, aquí solamente se trabajarán los artículos relativos al problema de la clonación humana de manera más abarcadora, que son: Artículo 25: Art. L. 2151-1; Art. L. 2151-2; Art. L. 2151-3; Art. L. 2151-4; Art. L. 2151-5. Artículo 28: Art. 214-2; Art. 215-4; Art. 511-1; Art. 511-1-1; 511-17; Art. 511-18; Art. 511-18-1. Artículo 29: Art. 511-1-2.

Desde el punto de vista de los significados textuales puede verse que predominan netamente los temas tópicos no-marcados, con dos casos de temas marcados y otros dos de temas textuales. Sobre todo en las frases pasivas ("est interdit/e" y "est puni/e") se observa que los autores suelen poner los mismos contenidos, a veces en posición de rema y otras de tema, de manera que el verbo que expresa la prohibición puede permanecer solo en posición de tema o de rema. Por esta razón se alternan continuamente temas cortos y largos y, por consiguiente, remas cortos y largos.

Por su parte, el análisis de los significados ideacionales muestra una fuerte metaforización de los procesos (78\%) y un predominio casi absoluto de los materiales. Esto podría hablar de una especie de "depuración” jurídica del lenguaje, por la cual se eliminan los posibles componentes interpersonales que pueden implicar los procesos mentales y verbales, arribando a un discurso más abstracto. Por otra parte, los sujetos gramaticales 
de estos procesos son todos objetos, abstracciones o procesos nominalizados, donde no aparece ningún actor humano o institución. En este sentido, el legislador también ha operado en pos de una depuración de los sujetos, utilizando siempre las mismas fórmulas.

En relación con esto último, las modulaciones que expresan las prohibiciones y las penas han sido igualmente homogeneizadas. Este proceso se da a través del uso continuo de la forma pasiva ("est interdit/e" y "est puni/e"), que en realidad es una forma metafórica de expresar la orden, la cual permite eliminar toda referencia a actores concretos, contrariamente al futuro del indicativo, utilizado en muchos proyectos de ley de la Argentina, el cual requiere alguna referencia a personas — aunque más no sea un pronombre relativo. La forma más congruente, el imperativo, se encuentra completamente ausente en estos artículos, ya que en los demás casos se emplean otros giros para expresar órdenes. Algunos de ellos se encuentran más metaforizados como el "ne peut être ni conçu, ni constitué par clonage, ni utilisé" del artículo 2151-3, o el "ne commence à courir" del artículo 215-4.

Desde el punto de vista semántico, la ley prohíbe hacer nacer un individuo genéticamente idéntico a otro, la creación de un embrión con fines terapéuticos o de investigación, y la concepción, constitución y utilización de un embrión para fines industriales y comerciales. En cuanto a las penas, un caso de clonación reproductiva implicaría treinta años de prisión y una multa de 7.500.000 euros para el culpable, mientras que prestarse a una extracción de células o gametos para el fin anteriormente mencionado conlleva una pena de diez años de prisión y una multa 150.000 euros. Por otro lado, la constitución de embriones humanos por clonación con fines industriales o comerciales, terapéuticos y de investigación comporta una pena de siete años de prisión y una multa de 100.000 euros. Además, también se castiga con tres años de reclusión y una multa de 45.000 euros el incitar a otro para que se preste a la mencionada extracción de células o gametos, con el objetivo de hacer nacer una persona genéticamente idéntica a otra. Por último, la ley también castiga con la misma pena la propaganda o publicidad a favor del eugenismo y la clonación reproductiva.

Como puede observarse, esta ley es altamente específica y amplía la clásica dicotomía entre clonación reproductiva y terapéutica, introduciendo la clonación con fines comerciales o industriales, y la abocada a la investigación. Por otra parte, la ley no descuida el punto de las penas, que son de las más severas del mundo. Asimismo, hasta la misma propaganda o publicidad es contemplada por esta ley, aspecto que puede haber sido incorporado por la repercusión mediática de los dichos de la secta raeliana, cuyo fundador es, precisamente, un francés.

\subsection{Ley $\mathrm{N}^{0} 11.105$ de Brasil (2005)}

La ley 11.105, del 24 de marzo de 2005 prohíbe la clonación reproductiva y autoriza la terapéutica. En relación con este tema, la ley es sumamente sintética. El análisis de los significados textuales muestra cierta disparidad estructural entre los artículos $3^{\circ}, 6^{\circ}$ y $26^{\circ}$, que son aquellos que tratan la cuestión. En el primero de ellos se prefiere comenzar con un tema tópico marcado y un largo rema, en el que se incluyen tres definiciones. Por el contrario, en el $6^{\circ}$, se utiliza un tema no-marcado y el último no permite un análisis de este tipo, ya que ni siquiera presenta un verbo conjugado. Por su parte, el plano ideacional muestra un altísimo grado de nominalización de los procesos, ya que en los fragmentos seleccionados solamente se encuentran dos verbos conjugados, que son un mental y un material. En el 
plano interpersonal solamente el artículo $6^{\circ}$ presenta una clara modulación, aunque metaforizada, producto de la utilización del giro "fica proibido", mediante el cual la prohibición es objetivizada y abstraída respecto de los actores que la hacen posible y la imponen. Por el contrario, en el artículo $26^{\circ}$ se ha optado por una forma más objetivizada, prefiriéndose un lenguaje telegráfico, sin verbos conjugados.

Desde el punto de vista semántico, una de las particularidades de esta ley es su extrema síntesis y simpleza, lograda, en gran parte, a través de la utilización de un lenguaje poco específico. En este sentido, una de las singularidades de la ley es la incorporación de definiciones, que distan mucho de representar ampliamente la complejidad de las técnicas bajo análisis. Esta misma simplicidad, que hace al texto fácilmente entendible, puede ser también a futuro un punto débil, debido a que la poca refinación las definiciones utilizadas puede llevar a que ciertas prácticas que se tenía la intención de prohibir, no queden incluidas en la misma. En cuanto al tema de las penas, aquí también se sanciona con un máximo de cinco años de reclusión la creación de un ser humano mediante clonación, la cual parece ser la pena que más consenso genera.

\subsection{La ley 20120 de Chile (2006)}

La ley 20120 “Sobre la investigación científica en el ser humano, su genoma, y prohíbe la clonación humana" de Chile reprime todo tipo de clonación humana a través de los artículos $5^{\circ}$ y $17^{\circ}$. Desde el punto de vista textual, estos artículos despliegan elecciones diferentes. El primero de ellos sigue el mismo modelo que se observa en gran parte de los proyectos de ley argentinos que intentan prohibir esta práctica, utilizando un tema tópico no-marcado muy corto, de una o dos palabras, y un rema también corto. El segundo artículo presenta una estructura diferente, utilizando un tema tópico no-marcado largo y otro tema marcado, más corto. En cuanto al plano ideacional, casi todos los procesos son materiales, con una tendencia a preferir la metaforización de los mismos. Por su parte, el análisis del mood marca que los sujetos gramaticales preferidos son personas abstractas ("el que..."), y en menor medida los sujetos indeterminados. Esta inclusión de personas abstractas está en relación con la forma de expresar la modulación preferida en el artículo $17^{\circ}$, que es a través del futuro pasivo ("será castigado", "será sancionado"). Por su parte, el artículo $5^{\circ}$ expresa la prohibición a través del presente del indicativo ("prohíbese"), forma menos metaforizada que la anteriormente citada. Debe notarse que estas fórmulas son las mismas que se han utilizado en varios de los proyectos de ley argentinos (Calise, 2014), siendo la forma de redacción muy similar en ambos países.

En cuanto a la condena, puede notarse que ésta sigue la postura de la mayoría antes señalada, ya que esta va de los 541 días a los 5 años. Además, los infractores serán sancionados con inhabilitación para ejercer su profesión, cosa que fue omitida por algunos legisladores.

\subsection{Legislación de España}

La legislación española relativa a la clonación ha sufrido diferentes modificaciones en las últimas décadas, al tiempo que no se encuentra unificada como la francesa. Hoy en día se cuenta con la Ley 14/2006, del 26 de mayo sobre técnicas de reproducción humana asistida, que prohíbe la clonación humana reproductiva, y contempla también una sanción administrativa, no de naturaleza penal. Esta última se encuentra en la Ley Orgánica 15/2003 
del 25 de noviembre (por la que se modifica la Ley Orgánica 10/1995, del 23 de noviembre, del Código Penal). Por otra parte, la Ley 14/2007 del 3 de julio de Investigación biomédica permite "la activación de ovocitos mediante transferencia nuclear", con fines terapéuticos o de investigación.

Si se comparan los significados textuales en el artículo 1 de la ley 14/2006 y el artículo 33 de la 14/2007, se observa que ambas prohibiciones utilizan la misma estructura, o sea, un tema corto constituido por el "se prohíbe" y un rema también corto. Por el contrario, el permiso otorgado a la clonación terapéutica y de investigación, si bien utiliza también un tema corto de la misma naturaleza ("se permite"), se complementa con un rema mucho más largo. Lo mismo ocurre en los puntos 1 y 2 del artículo 1 de la primera ley citada, de naturaleza más descriptiva. Más dispar es la estructura temática de las prohibiciones expresadas en el artículo 56 de la Ley Orgánica 15/2003, ya que en el punto uno se prefiere un tema tópico no-marcado largo, mientras que en el segundo, uno corto, y en el tercero uno marcado corto, pese a que en todos los casos se expresan penas a través del "se castigará" o "será castigado".

Desde el punto de vista ideacional, en los artículos antes citados se observa una preferencia por la nominalización de los procesos (78\% se encuentran nominalizados), y un dominio general, entre procesos metaforizados y no-metaforizados, de los significados materiales.

Por último, los significados interpersonales muestran la presencia de ciertas modalizaciones expresadas a través del modo subjuntivo. Ellas se ausentan en las prohibiciones, mientras que aparecen esporádicamente en los demás artículos. Por su parte, para las modulaciones que indican prohibiciones se utiliza nuevamente el presente de indicativo, evitando el imperativo directo. Más metaforizada se encuentra la expresión del castigo a través del futuro pasivo y en un caso del futuro en forma activa. A través de esta forma de expresión la orden se diluye, asumiendo la apariencia de una condición.

A nivel semántico, se observa que España fue adquiriendo una posición menos severa respecto de la clonación con el paso del tiempo. La clonación reproductiva ha quedado claramente prohibida (14/2006, art 1.3), incluyendo para los infractores sanciones pecuniarias de entre 10.001 euros hasta un millón de euros (14/2006, art. 27), con penas de prisión de "uno a cinco años e inhabilitación especial para empleo o cargo público, profesión u oficio de seis a 10 años". Si se compara con lo establecido por el sistema político francés, las penas y sanciones españolas pueden resultar irrisorias. Por otra parte, las innovaciones introducidas por la ley 14/2007 hacen posible la utilización de la clonación con fines terapéuticos o de investigación, contrariamente a lo establecido por el legislador francés. Por otra parte, a través de estas leyes España ha permitido la utilización de embriones para fines terapéuticos o investigativos, siempre y cuando no sean creados nuevos embriones para satisfacer tales objetivos.

\subsection{La legislación británica}

La legislación británica ha cambiado durante las últimas décadas. La Human Reproductive Cloning Act de 2001 venía a complementar la Human Fertilisation and Embryology Act de 1990. A través de la primera quedaba prohibida y penada la clonación humana reproductiva. Sin embargo, por medio de la Human Fertilisation and Embryology Act de 2008, que vino a reformar a su antecesora de 1990, se ha derogado la mencionada ley de 2001. Esto 
no quiere decir que la clonación reproductiva esté ahora permitida, sino que, a través de una redacción más compleja y específica, y omitiendo su explícita referencia, se ha arribado al mismo resultado. A continuación se analizarán las secciones 3.2 y $3 Z$ A de la ley de 2008 , y las correspondientes penas detalladas en el artículo 41 de la de 1990.

Desde el punto de vista temático, para la redacción de la última ley mencionada se ha preferido la utilización de un tema tópico no-marcado largo y otro corto (y un textual en el medio). Mientras que en la otra ley son todos los temas tópicos no-marcados cortos, combinados con temas textuales, que señalan adición o disyunción. Esta marcada presencia de temas textuales indica la existencia de una estructura diferente, no utilizada por la demás legislación. El uso de una puntuación compleja y de párrafos unioracionales, que es una característica general del discurso jurídico en general (García, 2013), vuelve el texto complejo a una primera lectura, hasta que el lector comprende la lógica discursiva que el legislador eligió a la hora de la redacción. Esta estructuración lo aparta de los demás textos y de la ley anterior de 1990. Este alejamiento parece ser explícitamente buscado, con el objetivo de poder superar las ambigüedades que las formas más comunes de legislar la problemática de la clonación presentan para el lenguaje legislativo.

Por su parte, los significados ideacionales muestran otra particularidad, la fuerte presencia de procesos relacionales $(35 \%)$, pese al predominio de los materiales. Lo que resulta curioso es la falta de todo el vocabulario ligado a las técnicas científicas y a la investigación, más allá de los sustantivos que indican las diferentes entidades que intervienen en los procesos. Esta alta refinación del lenguaje, que podría parecer a primera vista una simplificación y trivialización de la cuestión, permite desligar las conductas prohibidas de los conocimientos y técnicas disponibles hasta hoy, haciendo la ley menos ambigua y más abarcadora, al tiempo que más complicada de interpretar con una simple lectura.

Por otra parte, el análisis del mood muestra que los sujetos son, en todos los casos, abstractos. Priman los sujetos ligados al lenguaje de la genética (ovocitos, esperma, embrión, etc.), y toda referencia humana es también abstracta (persona, hombre, mujer), pero, contrariamente a lo que sucede en otras leyes, la abstracción no se da como resultado de la preferencia por utilizar masivamente nominalizaciones o conceptos como sujeto gramatical.

Por último, en el plano interpersonal se puede encontrar la presencia de algunas modalizaciones en los artículos analizados de la ley de 2008 ("may provide", "can be"), que son utilizadas para dar cuenta de un caso hipotético, la autorización de alterar ovocitos o embriones con el fin de evitar una enfermedad mitocondrial "seria". Este último elemento también tiene un carácter modal, al tiempo que no se especifica qué es "serio" y qué no lo es, y, en todo caso, quién puede realizar tal evaluación. Pasando al análisis de las modulaciones, el artículo 41 utiliza la forma pasiva para expresar la culpabilidad, metaforizando de manera clara la prohibición. Además se emplea un verbo modal en forma negativa ("cannot be authorized") para completar la situación. La otra ley utiliza la fórmula "shall place", que combina cierto valor de futuro de la forma "shall", con una connotación de deber. Puede notarse que ambos giros comienzan poniendo un sujeto humano abstracto ("a person", "no person"), lo cual permite borrar toda referencia a los sistemas político y jurídico, que parecerían no tener ninguna participación. De esta manera, las prohibiciones se presentan como abstractas y naturales, consecuencia de las prácticas erradas de los hombres.

Desde el punto de vista semántico, esta serie de elecciones léxico-gramaticales han producido un texto que se aleja de las demás leyes referidas a estos problemas. En efecto, 
los artículos aquí analizados de la ley de 2008 parecen más una clasificación que verdaderas leyes. Por otra parte, en cuanto al problema de la clonación, pese a que no resulta difícil deducir la prohibición del texto, la ley no menciona explícitamente a esta técnica como prohibida, sino que ella queda prohibida porque no satisface el punto 2, o sea, porque esta técnica produce ovocitos no-permitidos, ni tampoco el punto 4, porque no genera un embrión permitido. A través de esta formulación mucho más compleja, parecería ser que el legislador ha buscado evitar la mención de técnicas concretas, con el fin de que el avance científico no vuelva rápidamente obsoleta la ley. Esta es la posible causa por la cual se prefirió abolir la ley sobre clonación reproductiva de 2001. Por el lado de las penas, estas pueden ser más duras que las establecidas por España o Alemania, pero menos severas que las indicadas por Francia, pudiendo castigarse un caso de clonación reproductiva con hasta diez años de reclusión y una multa. En cuanto a la clonación terapéutica o con fines de investigación, debe notarse que el "Human Fertilisation and Embryology Authority" (HFEA), ya en 2004 otorgó una licencia para crear células madre embrionales a través de la técnica de transferencia nuclear, de manera que, siempre bajo autorización, se encuentra permitida.

\section{Conclusiones: del texto al contexto}

Como se ha podido apreciar a lo largo de este trabajo, existen ciertas elecciones léxicogramaticales que tienden a ser comunes en estas leyes. Ejemplos de esto son la preferencia de los temas tópicos no-marcados cortos, sobre todo a la hora de expresar la prohibición de la clonación, la fuerte tendencia a metaforizar los procesos, al tiempo que se prefieren claramente los significados materiales. Puntualizando en el plano ideacional, otra predisposición repetidamente marcada es la de metaforizar continuamente muchos de los significados ligados a la clonación y a la ciencia, mientras que los procesos que expresan acciones y reacciones de los sistemas político y jurídico suelen ser enunciados con mucha más frecuencia de manera no-metaforizada. Algunos ejemplos de esto son:

1. it has been created by the fertilisation of a permitted egg by permitted sperm

2. La recherche sur l'embryon humain est interdite.

3. La activación de ovocitos mediante transferencia nuclear para su uso con fines terapéuticos o de investigación

4. Prohíbese la clonación de seres humanos, cualesquiera que sean el fin perseguido y la técnica utilizada.

5. The Minister may permit research on stem cells and zygotes which are not more than 14 days old on a written application

En estos casos la fertilización, investigación, activación de ovocitos o clonación son todos procesos que aparecen permanentemente de forma metaforizada. Por su parte las acciones del sistema político y jurídico se manifiestan típicamente a través de la forma impersonal "se" (en castellano) o de forma más explícita, como ha preferido hacerlo el legislador sudafricano indicando al ministro como sujeto explícito de la acción.

Traduciendo los resultados del análisis en cifras, se observa una clara prevalencia de los procesos metaforizados por sobre los no-metaforizados en todos los textos, al mismo tiempo que la mayoría de estos procesos son de naturaleza material. 


\begin{tabular}{|l|c|c|c|c|c|c|c|c|}
\hline & Alemania & Argentina & Brasil & Chile & España & Francia & $\begin{array}{c}\text { Reino } \\
\text { Unido }\end{array}$ & Sudáfrica \\
\hline Procesos & $43 \%$ & $38 \%$ & $9 \%$ & $40 \%$ & $22 \%$ & $22 \%$ & $47 \%$ & $30 \%$ \\
\hline $\begin{array}{l}\text { Procesos } \\
\text { metaforizados }\end{array}$ & $57 \%$ & $62 \%$ & $91 \%$ & $60 \%$ & $78 \%$ & $78 \%$ & $53 \%$ & $70 \%$ \\
\hline
\end{tabular}

Cuadro 1: Porcentaje de procesos metaforizados y no metaforizados.

\begin{tabular}{|l|c|c|c|c|c|c|c|c|}
\hline & Alemania & Argentina & Brasil & Chile & España & Francia & $\begin{array}{c}\text { Reino } \\
\text { Unido }\end{array}$ & Sudáfrica \\
\hline Material & $83 \%$ & $65 \%$ & $50 \%$ & $87,5 \%$ & $68 \%$ & $95 \%$ & $61 \%$ & $65 \%$ \\
\hline Mental & $0 \%$ & $9 \%$ & $50 \%$ & $0 \%$ & $0 \%$ & $0 \%$ & $4 \%$ & $12 \%$ \\
\hline Verbal & $0 \%$ & $13 \%$ & $0 \%$ & $0 \%$ & $8 \%$ & $0 \%$ & $0 \%$ & $0 \%$ \\
\hline Relacional & $17 \%$ & $13 \%$ & $0 \%$ & $12,5 \%$ & $15 \%$ & $5 \%$ & $35 \%$ & $25 \%$ \\
\hline Existencial & $0 \%$ & $0 \%$ & $0 \%$ & $0 \%$ & $8 \%$ & $0 \%$ & $0 \%$ & $0 \%$ \\
\hline
\end{tabular}

Cuadro 2: Significados experienciales en porcentajes.

\begin{tabular}{|l|c|c|c|c|c|c|c|c|}
\hline & Alemania & Argentina & Brasil & Chile & España & Francia & $\begin{array}{c}\text { Reino } \\
\text { Unido }\end{array}$ & Sudáfrica \\
\hline Material & $75 \%$ & $83 \%$ & $100 \%$ & $100 \%$ & $89 \%$ & $95 \%$ & $88 \%$ & $95 \%$ \\
\hline Mental & $0 \%$ & $3 \%$ & $0 \%$ & $0 \%$ & $4 \%$ & $0 \%$ & $4 \%$ & $0 \%$ \\
\hline Verbal & $12,5 \%$ & $6 \%$ & $0 \%$ & $0 \%$ & $4 \%$ & $2,5 \%$ & $12 \%$ & $0 \%$ \\
\hline Relacional & $12,5 \%$ & $8 \%$ & $0 \%$ & $0 \%$ & $4 \%$ & $0 \%$ & $0 \%$ & $5 \%$ \\
\hline Existencial & $0 \%$ & $0 \%$ & $0 \%$ & $0 \%$ & $0 \%$ & $2,5 \%$ & $0 \%$ & $0 \%$ \\
\hline
\end{tabular}

Cuadro 3: Significados experienciales metaforizados en porcentajes.

Continuando con el análisis del plano ideacional, al examinar los sujetos gramaticales de los procesos no se encuentran tendencias tan claras como en el caso de los procesos. No obstante, la preferencia por la abstracción es clara, debido a que los legisladores han seleccionado como sujetos gramaticales a procesos, conceptos, cosas, abstracciones, personas abstractas y, en la legua castellana y portuguesa, al "se". Esto se da en detrimento de personas concretas (el presidente, el ministro) y de organizaciones específicas (una comisión, un ministerio).

Esta prevalencia se puede interpretar como un indicador más de la preferencia de los autores por la abstracción, que se correlaciona con la tendencia generalizada a nominalizar los procesos. Esta correspondencia entre ambos no solamente subyace en que estas dos elecciones discursivas contribuyen a hacer el texto más abstracto, sino que, en numerosas ocasiones, estas mismas nominalizaciones se vuelven sujetos gramaticales. Una tendencia similar puede ser interpretada, desde la lingüística sistémico-funcional, como una estrategia de "ocultamiento" del individuo que realiza la acción. En relación con esto último, el "se" también oculta a los legisladores que se encargan de redactar y promulgar la ley, o sea, al sistema político que produce la ley, y al sistema jurídico que se encargará de sancionar a los infractores. Esta preferencia por la abstracción y el ocultamiento de los actores concretos es uno de los rasgos típicos del género del cual forma parte el texto, propiedad que comparte con los textos científicos. 


\begin{tabular}{|l|c|c|c|c|c|c|c|c|}
\hline & Alemania & Argentina & Brasil & Chile & España & Francia & $\begin{array}{c}\text { Reino } \\
\text { Unido }\end{array}$ & Sudáfrica \\
\hline $\begin{array}{l}\text { Conceptos, } \\
\text { abstracciones y } \\
\text { cosas }^{5}\end{array}$ & $12,5 \%$ & $30 \%$ & $0 \%$ & $12,5 \%$ & $54 \%$ & $100 \%$ & $79 \%$ & $35 \%$ \\
\hline $\begin{array}{l}\text { Personas } \\
\text { concretas }\end{array}$ & $12,5 \%$ & $4 \%$ & $0 \%$ & $0 \%$ & $0 \%$ & $0 \%$ & $0 \%$ & $12 \%$ \\
\hline $\begin{array}{l}\text { Personas } \\
\text { abstractas }\end{array}$ & $67 \%$ & $0 \%$ & $0 \%$ & $62,5 \%$ & $15 \%$ & $0 \%$ & $21 \%$ & $47 \%$ \\
\hline Organizaciones & $0 \%$ & $35 \%$ & $0 \%$ & $0 \%$ & $0 \%$ & $0 \%$ & $0 \%$ & $0 \%$ \\
\hline "se" & $0 \%$ & $30 \%$ & $50 \%$ & $12,5 \%$ & $31 \%$ & $0 \%$ & $0 \%$ & $0 \%$ \\
\hline Indeterminado & $0 \%$ & $0 \%$ & $50 \%$ & $0 \%$ & $0 \%$ & $0 \%$ & $0 \%$ & $6 \%$ \\
\hline
\end{tabular}

Cuadro 4: Sujetos de los procesos no-nominalizados.

Por último, en el plano interpersonal, se ha notado una muy baja cantidad de modalizaciones, sobre todo en los artículos que expresan prohibiciones, mientras que las modulaciones no han sido expresadas en casi ninguna ocasión a través de la forma más congruente, el imperativo. A la hora de pronunciar una prohibición, los legisladores que se expresan en castellano y portugués han elegido el presente de indicativo seguido o antecedido por el "se" (al menos en castellano y portugués). En francés y en alemán ha imperado la voz pasiva, tanto a la hora de prohibir como de castigar, mientras que en inglés se ha optado por el "shall" (Reino Unido) y el "may" (Sudáfrica). Algunos ejemplos de esto son los siguientes:

1. Se prohíbe la clonación en seres humanos con fines reproductivos.

2. No person shall place in a woman-

(a) an embryo other than a permitted embryo (as defined by section 3ZA), or

(b) any gametes other than permitted eggs or permitted sperm (as so defined).

3. Est interdite toute intervention ayant pour but de faire naître un enfant génétiquement identique à une autre personne vivante ou décédée.

4. No person may import or export human zygotes or embryos without the prior written approval of the Minister.

Más allá de estas coincidencias y de las posibles divergencias puntuales ya marcadas, el análisis de la legislación muestra que la clonación no es tratada por el sistema político de manera aislada, como sucede en el caso argentino, sino que la reflexión sobre el tema forma parte de conjuntos de leyes mucho más abarcadores. En el caso alemán, ésta forma parte de una ley dedicada a tratar los problemas ligados con la protección de los embriones

5 En los casos en los que el embrión, el ovocito o el esperma ocupan la función de sujeto gramatical se los ha contabilizado dentro de esta categoría. Naturalmente que esto tiene implicancias ético-filosóficas, ya que muchos eticistas y juristas consideran que un embrión o un ovocito serían una persona. A este respecto, Ciuro Caldani (2001: 75) señala que el lenguaje de la bioética contiene una gran carga de valores, por lo que resulta imposible comprender la problemática bioética sin replantearse el despliegue de estos valores. En este caso intentaremos dejar de lado la discusión de los valores para observar qué tipo de procesos encabezan estos sujetos. Lo que se puede ver es que la mayoría de ellos son procesos relacionales utilizados para dar una definición ("An embryo is a permitted embryo if...”; “A permitted egg is one ...") y no materiales que expresan las acciones que realizan tales entidades. Es por esta razón que nos parece inapropiado asimilarlos a personas abstractas. 
(que comprende cuestiones de reproducción, investigación y terapia), la ley brasileña, por su lado, toca el tema como parte de cuestiones relacionadas con la bioseguridad y la biotecnología, mientras que, por ejemplo, la ley británica aborda el problema en el contexto de la fertilidad humana y la embriología. En síntesis, ninguno de estos países — sea americano, europeo o africano - ha legislado puntualmente sobre la cuestión de la clonación de forma aislada, con la excepción de la ley británica de 2001, que ya ha sido abolida y superada por una nueva legislación.

Un problema diferente es el de la graduación de las penas. En el siguiente cuadro se sintetiza la información respecto de las penas de reclusión en la legislación analizada.

\begin{tabular}{|c|c|c|c|c|c|c|c|}
\hline País & Alemania & Sudáfrica & Brasil & Chile & España & $\begin{array}{c}\text { Gran } \\
\text { Bretaña }\end{array}$ & Francia \\
\hline $\begin{array}{c}\text { Penas de } \\
\text { prisión }\end{array}$ & $0-5$ años & $\begin{array}{c}\text { Hasta 5 } \\
\text { años }\end{array}$ & $\begin{array}{c}2-5 \\
\text { años }\end{array}$ & $\begin{array}{c}541 \text { días } \\
-5 \text { años }\end{array}$ & $\begin{array}{c}1-5 \\
\text { años }\end{array}$ & $\begin{array}{c}0-10 \\
\text { años }\end{array}$ & $\begin{array}{c}-30 \text { años (por hacer } \\
\text { nacer) } \\
-10 \text { años (prestarse } \\
\text { a la extracción de } \\
\text { células o gametos) } \\
-7 \text { años (fines in- } \\
\text { dustriales, comer- } \\
\text { ciales, terapéuti- } \\
\text { cos y de investi- } \\
\text { gación) } \\
\text { años (provocar, } \\
\text { hacer propaganda } \\
\text { o publicidad) }\end{array}$ \\
\hline
\end{tabular}

Cuadro 5: Penas de prisión para el delito de clonación ${ }^{6}$.

Como puede apreciarse en el cuadro anterior no existe una uniformidad de criterios a la hora de imponer penas para el delito de clonación, más allá de que la muestra de legislación no es estadísticamente representativa y no permite deducir una tendencia. Sorprende observar que dos países tan cercanos en muchos aspectos, como Francia y Alemania, prescriban penas tan extremadamente disímiles. En el caso alemán resultan equiparables a un delito menor (por ejemplo el robo, en el Código Penal argentino), mientras que en el caso francés el castigo resultaría más alto que la máxima pena imponible por un delito contra la vida (siguiendo el mismo Código). Por lo tanto, para el legislador francés es igualmente grave (según lo establecido por el Código Penal de ese país) matar voluntariamente a una persona, que dar vida a otra a través de la técnica bajo análisis. En efecto, en el Código Penal francés la clonación entra dentro de la categoría "delitos contra la especie humana". Por otra parte,

6 Ya que la Argentina no cuenta con legislación, no se la ha incluido en el cuadro. Sin embargo hay cuatro proyectos que no lograron convertirse en ley, donde se especifican penas. Ellos son 2530-D-04: pena de prisión 1-5 años; 0100-S-03 pena de prisión 4-10 años; 6216-D-01 pena de prisión 3-10 años (investigación en células humanas) y 10-20 años (si se clona un humano); 0559-D-02 pena de prisión 8-20 años. Estos datos no han sido incorporados al análisis para no confundir la diferente naturaleza de una ley con un proyecto de ley descartado por el legislador. 
debe notarse que, a excepción del caso francés, toda la otra legislación solamente reprime a quien realiza la acción de clonar, o sea, a los profesionales médicos y de otras profesiones relacionadas. Esto significa que, para la mayoría de los países, aquel que debe ser reprimido es solamente quien realiza la acción y no quien, por ejemplo, busca la ayuda de tal profesional para poder concebir un hijo.

Este panorama hace pensar, con la ayuda de Neves (1994: 31), en que la legislación en torno de la clonación tiene un claro componente simbólico, más allá de que algunas leyes parezcan ser mucho más eficaces que otras. Neves define la legislación simbólica como aquella producción de textos que hace referencia manifiesta a la realidad normativo-jurídica, pero que sirve, primaria e hipertróficamente, a finalidades políticas de carácter no específicamente normativo-jurídica. Por consiguiente, sus principales características son la de ser normativamente ineficaz y carecer de vigencia social, aunque para el sistema político ella es capaz de producir efectos relevantes, de naturaleza no específicamente jurídica. A nivel social, y entre otras cosas, sirve para convencer a las personas y grupos de la consistencia del propio comportamiento y de las normas que valoran positivamente, dándoles la tranquilidad de que sus sentimientos e intereses se encuentran incorporados y garantizados por el derecho.

Por su parte, la constitución simbólica (Neves, 1994: 83) se define como aquel texto constitucional que no llega a concretizarse normativo-jurídicamente de manera generalizada. A este texto, señala Neves, le falta normatividad, ya que no se le corresponden expectativas normativas congruentemente generalizadas. Esto significa que los procedimientos y argumentos específicamente jurídicos no tendrían relevancia funcional en relación con los hechos del entorno. Consiguientemente, se da un desfasaje entre el texto y la praxis de las organizaciones estatales, las cuales lo socavan y violan continua y casuísticamente. De esta manera, la constitución pierde su función de direccionar las conductas y orientar las expectativas conforme a determinaciones jurídicas de los respectivos dispositivos constitucionales, y pasa a responder a las exigencias y objetivos políticos concretos. En este sentido, el discurso del poder la invoca continuamente como aquella estructura normativa que garantiza los derechos fundamentales, la división de poderes y las elecciones democráticas, al mismo tiempo que, retóricamente, se destaca que estas instituciones son conquistas del Estadogobierno y pruebas de la existencia de la democracia en el país. No obstante, esta función ideológica de la constitucionalización simbólica tiene límites, por lo cual tal situación podría conducir a la desconfianza pública generalizada en el sistema político y en las agencias del Estado, y a la consiguiente toma de conciencia por parte del público de la discrepancia entre la política real y el discurso constitucionalista.

La legislación simbólica tiene una finalidad centralmente política. Una de las funciones principales de este tipo de legislación destacado por Neves (1994: 34) es el de confirmar los valores sociales en un contexto de lucha por la prevalencia de algunos de ellos. En este sentido, la "victoria legislativa" manifiesta la superioridad o el predominio social de la concepción valorativa del sector que termina por imponerla. Si se revisan los trabajos de Mulkay citados en la introducción puede observarse cómo la legislación sobre las técnicas de reproducción asistida en Inglaterra implicó un fuerte enfrentamiento entre diferentes sectores políticos, representantes de sus correspondientes y más amplios agrupamientos sociales. La definición del concepto de pre-embrión, plasmado en el Warnock Report, implicó la victoria de los partidarios de la intervención sobre estos seres en detrimento de las airadas críticas 
de sectores religiosos y laicos. Los debates fueron acalorados y ampliamente cubiertos por los medios de masas. Por otro lado, las fuertes penas impuestas en Francia, tal como se comentaba anteriormente, también podrían expresar un cierto carácter simbólico. Mostrando el fuerte rechazo del Estado se comunica a la sociedad que no se permitirán tales abusos a nadie, ni a los médicos, ni a los interesados, ni a ningún ciudadano francés en cualquier parte del mundo. Si se considera que la amenaza de clonar seres humanos llevada a cabo por la secta de los raelianos ${ }^{7}$ en años anteriores a la promulgación de la ley fue solamente un evento mediático sin implicar un real peligro, parece excesiva la severidad de la ley.

El intento de legislar la clonación en Argentina a través del decreto 200/97 es, seguramente, el caso más marcado de legislación simbólica. Por un lado, corrobora el predominio de un sector social de clara inspiración católica, contrario al aborto, a las técnicas de fecundación asistida y a cualquier intervención sobre el embrión, dentro de la doctrina jurídica. Este decreto fue sancionado el mismo año del anuncio del nacimiento de la oveja Dolly, con lo cual se dejó poco lugar para la discusión respecto del tema, sino que se actuó apresuradamente intentando demostrar que la Argentina estaba "protegida" contra la ofensa a la dignidad humana que acarrearía tal práctica. En este sentido, el carácter simbólico también asumió una segunda forma, la de la legislación-coartada (Neves, 1994), en cuanto este decreto parece destinado a crear la imagen de un Estado que responde normativamente a los problemas reales de la sociedad. Por otra parte, el carácter simbólico más preocupante se ve nítidamente en su ineficacia. Como se indicaba más arriba, no solamente el decreto es una forma legal inadecuada para una prohibición, sino que también termina, virtualmente, prohibiendo prácticas socialmente aprobadas y necesarias, debido a su mala redacción.

Otra cuestión de importancia repetidamente señalada en las páginas anteriores es la tendencia generalizada a nominalizar todo aquello relacionado con el campo semántico de la clonación y la ciencia, mientras que los procesos que indican acciones del sistema político y jurídico tienden a asumir una forma más congruente. En principio, esta tendencia se ubica en un contexto donde abundan las nominalizaciones de todo tipo, no solamente referidas a los temas antes señalados. Para explicar este fenómeno es necesario retrotraerse a la diferencia esencial que Halliday encuentra entre la escritura y el habla (1990; 2003). El autor indica que estas dos formas de lenguaje entrañan dos gramáticas diferentes y dos visiones diferentes. El habla tiene una visión dinámica, ya que define al universo principalmente como proceso, codificándolo como construir o demoler. Para ella, los fenómenos no existen, sino que suceden. Como resultado se obtiene una pérdida de conciencia respecto de lo que son realmente las cosas en un punto real o imaginario del tiempo. Por el contrario, la escritura impone una visión sinóptica, definiendo al universo como producto y no como proceso, de manera que codifica todo como cosas que existen. Las consecuencias que conlleva esta forma de lenguaje son, por un lado, una cierta simplificación de la relación entre las partes $\mathrm{y}$, por otro, un menor interés en cómo algo ha adquirido la forma que tiene o en lo que

$7 \quad$ El tema de la clonación ha tenido su gran esplendor de la mano de la aparición de la famosa oveja escocesa Dolly, nacida en 1996 y fallecida en 2003. Un segundo gran período de debates y preocupación mundial sobrevino en 2002, cuando la secta de los raelianos y el doctor Antinori, informaron, cada uno por su lado, haber practicado inseminaciones con embriones clonados. Naturalmente, estos anuncios jamás superaron ese estatuto, pese a haber generado gran pánico en la sociedad y haber permitido recaudar importantes sumas de dinero. (http://www.lemonde.fr/planete/article/2002/12/27/ la-secte-raelienne-annonce-la-naissance-du-premier-clone-humain_303531_3244.html) 
devendrá a continuación. Desde un punto de vista histórico, el autor señala que, cuando el diálogo con la naturaleza se volvió un ejercicio consciente de comprensión, una sola gramática se mostró insuficiente, de manera que, desde una construcción activa de la realidad fue necesario optar por una perspectiva dinámica o una sinóptica. La primera de ellas es filogenéticamente anterior, ya que ha evolucionado anteriormente con la especie humana. Por el contrario, la segunda ha aparecido solamente en los últimos milenios. Esta última encarna una reflexión más consciente respecto del entorno, que es archivada bajo la forma de conocimientos científico. Desde un punto de vista histórico, ella deriva de la perspectiva dinámica por procesos de metaforización gramatical.

La importancia que Halliday (2004b) le da a la gramática subyace en su capacidad de transformar a la experiencia humana en significado, construyendo un universo de cosas y relaciones, imponiendo categorías sobre nuestra percepción de los fenómenos. Esto significa que erige una teoría de la experiencia. En el contexto de la gramática de la escritura, el grupo nominal reviste un rol preponderante, ya que éste, además del nombre central (que representa la "cosa") contiene otras funciones, como los clasificadores y epítetos. Por el contrario, el grupo verbal incluye un solo elemento léxico: el verbo. Es por esto que muchas cosas pueden ser dichas en el grupo nominal, especialmente en registros que tienen que ver con el mundo de la ciencia y la técnica, ya que las cosas e ideas que subyacen a ellas se encuentran en continua proliferación y multiplicación. En esta poderosa capacidad suya de generar significado se encuentra su posibilidad de expandirse prácticamente de manera indefinida. Este potencial de expansión estructural está relacionado con que el grupo nominal construye participantes, que son los elementos más estables en la escena experiencial, mientras que los procesos son naturalmente evanescentes.

En relación con la ciencia, Halliday (2004b) señala que la gradual destilación terminológica que comienza en la antigua Grecia produce abstracciones técnicas y permite el comienzo de la evolución de la teoría científica en Occidente. La nominalización es entonces el elemento central en el que se basa toda terminología técnica. Pero esta tecnicidad lingüística, por sí misma, no es suficiente si no viene acompañada de un discurso construido como flujo de argumentos basados en una progresión lógica. Cabe aclarar que este proceso no debe ser entendido como una creación aislada del discurso, sino que cada formulación introducida para favorecer el razonamiento es destilada gradualmente, hasta convertirse en una cosa nueva y virtual, que existe como parte de una teoría. Una vez concluido este proceso ya no es posible "desempacar" (unpack) el término, puesto que se encuentra metafóricamente muerto.

No obstante, estas reformulaciones metafóricas también introducen nuevos significados. Por un lado, cuando una cláusula es reformulada como un grupo nominal, se termina por ocultar gran parte de su información semántica. Por otra parte, la gramática nominal no es adecuada en la construcción primaria de la experiencia, de manera que es necesario, ya antes, conocer las respuestas. Esto lleva a que, lo que en un primer momento parecería ser una pérdida de significado, en realidad entraña un fuerte proceso de neutralización, que no deriva en la disminución de la distinción semántica, sino en el aumento de la ambigüedad, ya que los diferentes significados posibles se encuentran todavía diferenciados. Esta es una característica propia de la escritura científica (2004a), que se propone como un lenguaje para expertos, debido a que, si bien, por un lado, hace explícitas las interconexiones textuales y lógicas, también deja muchas ambigüedades puntuales. 
Lamentablemente, la lingüística sistémico-funcional no ha trabajado el caso de la escritura y el discurso jurídico, pero mucho de lo dicho anteriormente no es ajeno al derecho. Tanto la tendencia a la nominalización y a la consiguiente construcción de un vocabulario propio, como la propensión a desarrollar un discurso lógico, son elementos que han podido ser claramente apreciados en el análisis de las leyes. Además, justamente porque el tema tratado por el derecho en este caso es científico, la pertinencia de estas indicaciones se hace mayor, producto de la asimilación del lenguaje científico fuertemente nominalizado y de su discurso lógico. Entonces, en parte, puede explicarse la preferencia por metaforizar los procesos científicos como una especie de "importación" de nominalizaciones, que, en realidad, el sistema científico "exporta" a toda la sociedad. Nominalizaciones como "clonación", "investigación", "reproducción”, "trasplante”, y muchas otras, podrían considerarse como metáforas gramaticales muertas, ya que varias de ellas son más utilizadas que los mismos verbos de los cuales derivan. No obstante, esto no implica que dejen de ser consideradas como metáforas. Pero, por otro lado, también se nominalizan muchos otros procesos con un significado menos preciso, que, pese a estar ligado semánticamente a los procesos científicos, en esta ocasión, no pueden ser incluidos en su campo de significación. Nominalizaciones como "utilización”, "producción”, "desarrollo" y tantísimas otras (que son la mayoría), no pueden ser entendidas como meros casos de "importación", sino que son la expresión de las características propias del discurso jurídico mismo.

\section{Anexo: textos analizados}

\subsection{La Embryonenschutzgesetz de Alemania (1991)}

§ 1 Mißbräuchliche Anwendung von Fortpflanzungstechniken

(1) Mit Freiheitsstrafe bis zu drei Jahren oder mit Geldstrafe wird bestraft, wer

6. einer Frau einen Embryo vor Abschluß seiner Einnistung in der Gebärmutter entnimmt, um diesen auf eine andere Frau zu übertragen oder ihn für einen nicht seiner Erhaltung dienenden Zweck zu verwenden,

\subsection{Decreto 200/97 de Argentina}

Prohíbense los experimentos de clonación relacionados con seres humanos VISTO el expediente $N^{\circ}$ 2002-2657/97-1 del registro del MINISTERIO DE SALUD Y ACCION SOCIAL, y CONSIDERANDO:

Que es función indelegable del Estado la defensa de la dignidad de la persona humana, la preservación de su salud y la calidad de vida de los habitantes.

Que, asimismo, el Estado debe asegurar y garantizar el correcto empleo de los procedimientos y técnicas de uso y aplicación en los seres humanos.

Que los avances científicos que son de conocimiento público posibilitan la realización de experimentos de clonación humana que plantean problemas éticos y morales que se contraponen a las pautas y valores culturales propios de nuestro pueblo.

Que, por ello, resulta de urgente necesidad reglamentar, controlar y fiscalizar todas las actividades relacionadas con los experimentos de clonación, en particular con seres humanos. Que el Gobierno Nacional ha tomado conocimiento del impacto generado en la comunidad 
internacional como consecuencia de los avances científicos vinculados con la clonación. Que, igualmente, ha tomado conocimiento de las opiniones formuladas por representantes de distintos credos religiosos e instituciones científicas y de las decisiones adoptadas por gobiernos de diversos países fijando posiciones concretas al respecto.

Que, en tal sentido, ha recopilado la información pertinente que justifica la presente decisión, indicando al MINISTERIO DE SALUD Y ACCION SOCIAL que, previa consulta con la COMISION NACIONAL DE BIOETICA, que funciona en el ámbito de ese Ministerio, elabore un anteproyecto de ley sobre el tema para ser remitido al HONORABLE CONGRESO DE LA NACION.

Que el presente decreto se dicta en Acuerdo General de Ministros y en uso de las facultades conferidas por el artículo 99 inciso 3) de la CONSTITUCION NACIONAL.

Por ello,

EL PRESIDENTE DE LA NACION ARGENTINA

EN ACUERDO GENERAL DE MINISTROS

DECRETA:

Artículo $1^{\circ}$-Prohíbense los experimentos de clonación relacionados con seres humanos.

Art. $2^{\circ}$-Encomiéndase al MINISTERIO DE SALUD Y ACCION SOCIAL que, en un plazo no mayor de SESENTA (60) días, elabore el proyecto de ley respectivo.

Art. $3^{\circ}$-Dése cuenta al HONORABLE CONGRESO DE LA NACION en virtud de lo dispuesto por el artículo 99 inciso 3) de la CONSTITUCION NACIONAL.

Art. $4^{\circ}$-Comuníquese, publíquese, dése a la Dirección Nacional del Registro Oficial y archívese.-MENEM.-Carlos V. Corach.-Alberto Mazza.-Roque B. Fernandez.-José A. Caro Figueroa.-Susana B. Decibe.-Jorge M. R. Domínguez.-Guido J. Di Tella. T.E.C

Bs. As., 7/3/97

\subsection{La National Health Bill de Sudáfrica (2003)}

Prohibition of reproductive cloning of human beings

57.

(1) A person may not-

(a) manipulate any genetic material, including genetic material of human gametes, zygotes or embryos; or

(b) engage in any activity, including nuclear transfer or embryo splitting, for the purpose of the reproductive cloning of a human being.

(2) The Minister may, under such conditions as may be prescribed, permit therapeutic cloning utilising adult or umbilical cord stem cells.

(3) No person may import or export human zygotes or embryos without the prior written approval of the Minister.

(4) The Minister may permit research on stem cells and zygotes which are not more than 14 days old on a written application and if-

(a) the applicant undertakes to document the research for record purposes; and

(b) prior consent is obtained from the donor of such stem cells or zygotes.

(5) Any person who contravenes a provision of this section or who fails to comply therewith is guilty of an offence and is liable on conviction to a fine or to imprisonment for a period not exceeding five years or to both a fine and such imprisonment. 
(6) For the purpose of this section-

(a) "reproductive cloning of a human being" means the manipulation of genetic material in order to achieve the reproduction of a human being and includes nuclear transfer or embryo splitting for such purpose; and

(b) "therapeutic cloning" means the manipulation of genetic material from either adult, zygotic or embryonic cells in order to alter, for therapeutic purposes, the function of cells or tissues.

\subsection{Ley 2004-800 de Francia (2004)}

Article 25

«TITRE V

« RECHERCHE SUR L'EMBRYON ET LES CELLULES EMBRYONNAIRES

« Chapitre UNIQUE

« Art. L. 2151-1. - Comme il est dit au troisième alinéa de l'article 16-4 du code civil ci-après reproduit :

« Art. 16-4 (troisième alinéa). - Est interdite toute intervention ayant pour but de faire naître un enfant génétiquement identique à une autre personne vivante ou décédée. »

«Art. L. 2151-2. - La conception in vitro d'embryon ou la constitution par clonage d'embryon humain à des fins de recherche est interdite.

« Art. L. 2151-3. - Un embryon humain ne peut être ni conçu, ni constitué par clonage, ni utilisé, à des fins commerciales ou industrielles.

« Art. L. 2151-4. - Est également interdite toute constitution par clonage d'un embryon humain à des fins thérapeutiques.

« Art. L. 2151-5. - La recherche sur l'embryon humain est interdite.

Article 28

\section{« DES CRIMES CONTRE L'ESPÈCE HUMAINE \\ « Chapitre Ier \\ « Des crimes d'eugénisme et de clonage reproductif}

« Art. 214-2. - Le fait de procéder à une intervention ayant pour but de faire naître un enfant génétiquement identique à une autre personne vivante ou décédée est puni de trente ans de réclusion criminelle et de 7500000 EUR d'amende.

«Art. 215-4. - L'action publique relative aux crimes prévus par le présent sous-titre, ainsi que les peines prononcées, se prescrivent par trente ans.

« En outre, pour le crime de clonage reproductif prévu par l'article 214-2, le délai de prescription de l'action publique ne commence à courir, lorsque le clonage a conduit à la naissance d'un enfant, qu'à partir de la majorité de cet enfant. » 
« Art. 511-1. - Est puni de dix ans d'emprisonnement et de 150000 EUR d'amende le fait de se prêter à un prélèvement de cellules ou de gamètes, dans le but de faire naître un enfant génétiquement identique à une autre personne, vivante ou décédée. »;

«Art. 511-1-1. - Dans le cas où le délit prévu à l'article 511-1 est commis à l'étranger par un Français ou par une personne résidant habituellement sur le territoire français, la loi française est applicable par dérogation au deuxième alinéa de l'article 113-6 et les dispositions de la seconde phrase de l'article 113-8 ne sont pas applicables. »;

$4^{\circ}$ Le premier alinéa de 1'article 511-17 est ainsi rédigé :

« Le fait de procéder à la conception in vitro ou à la constitution par clonage d'embryons humains à des fins industrielles ou commerciales est puni de sept ans d'emprisonnement et de 100000 EUR d'amende. »;

« Art. 511-18. - Le fait de procéder à la conception in vitro ou à la constitution par clonage d'embryons humains à des fins de recherche est puni de sept ans d'emprisonnement et de 100000 EUR d'amende. »;

«Art. 511-18-1. - Le fait de procéder à la constitution par clonage d'embryons humains à des fins thérapeutiques est puni de sept ans d'emprisonnement et de 100000 EUR d'amende. »;

Article 29

«Art. 511-1-2. - Est puni de trois ans d'emprisonnement et de 45000 EUR d'amende le fait, par don, promesse, menace, ordre, abus d'autorité ou de pouvoir, de provoquer autrui à se prêter à un prélèvement de cellules ou de gamètes, dans le but de faire naître un enfant génétiquement identique à une autre personne vivante ou décédée.

« Est punie des mêmes peines la propagande ou la publicité, quel qu'en soit le mode, en faveur de l'eugénisme ou du clonage reproductif. »

\subsection{Ley $\mathrm{N}^{0} 11.105$ de Brasil (2005)}

Art. 3ํ Para os efeitos desta Lei, considera-se:

VIII - clonagem: processo de reprodução assexuada, produzida artificialmente, baseada em um único patrimônio genético, com ou sem utilização de técnicas de engenharia genética;

IX - clonagem para fins reprodutivos: clonagem com a finalidade de obtenção de um indivíduo;

X - clonagem terapêutica: clonagem com a finalidade de produção de células-tronco embrionárias para utilização terapêutica;

Art. 6o Fica proibido:

IV - clonagem humana;

Art. 26. Realizar clonagem humana:

Pena - reclusão, de 2 (dois) a 5 (cinco) anos, e multa. 


\subsection{La ley 20120 de Chile (2006)}

Artículo $5^{\circ}$.- Prohíbese la clonación de seres humanos, cualesquiera que sean el fin perseguido y la técnica utilizada.

Artículo 17.- El que clonare o iniciare un proceso de clonar seres humanos y el que realizare cualquier procedimiento eugenésico en contravención al artículo $3^{\circ}$, será castigado con la pena de presidio menor en su grado medio a máximo y con la inhabilitación absoluta para el ejercicio de la profesión durante el tiempo que dure la condena. En caso de reincidencia, el infractor será sancionado, además, con la pena de inhabilitación perpetua para ejercer la profesión.

\subsection{Legislación de España}

LEY 14/2006, de 26 de mayo, sobre técnicas de reproducción humana asistida.

\section{CAPÍTULO I}

Disposiciones generales

Artículo 1. Objeto y ámbito de aplicación de la Ley.

1. Esta Ley tiene por objeto:

a) Regular la aplicación de las técnicas de reproducción humana asistida acreditadas científicamente y clínicamente indicadas.

b) Regular la aplicación de las técnicas de reproducción humana asistida en la prevención y tratamiento de enfermedades de origen genético, siempre que existan las garantías diagnósticas y terapéuticas suficientes y sean debidamente autorizadas en los términos previstos en esta Ley.

c) La regulación de los supuestos y requisitos de utilización de gametos y preembriones humanos crioconservados.

2. A los efectos de esta Ley se entiende por preembrión el embrión in vitro constituido por el grupo de células resultantes de la división progresiva del ovocito desde que es fecundado hasta 14 días más tarde.

3. Se prohíbe la clonación en seres humanos con fines reproductivos.

\section{Artículo 26. Infracciones.}

1. Las infracciones en materia de la aplicación de las técnicas de reproducción asistida se califican como leves, graves o muy graves.

2. Además de las previstas en la Ley 14/1986, de 25 de abril, General de Sanidad, y de las tipificadas en la legislación de las comunidades autónomas, se consideran como infracciones leves, graves y muy graves las siguientes:

c) Son infracciones muy graves:

9. ${ }^{a}$ La práctica de técnicas de transferencia nuclear con fines reproductivos.

Artículo 27. Sanciones.

1. Las infracciones leves serán sancionadas con multa de hasta 1.000 euros; las graves, con multa desde

1.001 euros hasta 10.000 euros, y las muy graves, desde 10.001 euros hasta un millón de euros. 
En el caso de las infracciones muy graves tipificadas en el artículo 26.c) $2 .^{a}$ y $3 .^{\text {a }}$, además de la multa pecuniaria, se podrá acordar la clausura o cierre de los centros o servicios en los que se practiquen las técnicas de reproducción humana asistida. En el caso de la infracción grave tipificada en el artículo 26.b) 5.a, además de la multa pecuniaria, se podrá acordar en la resolución que imponga la sanción la revocación de la autorización concedida al centro o servicio de reproducción asistida.

2. La cuantía de la sanción que se imponga, dentro de los límites indicados, se graduará teniendo en cuenta los riesgos para la salud de la madre o de los preembriones generados, la cuantía del eventual beneficio obtenido, el grado de intencionalidad, la gravedad de la alteración sanitaria o social producida, la generalización de la infracción y la reincidencia.

3. En todo caso, cuando la cuantía de la multa resulte inferior al beneficio obtenido por la comisión de la infracción, la sanción será aumentada hasta el doble del importe en que se haya beneficiado el infractor.

4. Si un mismo hecho u omisión fuera constitutivo de dos o más infracciones, tipificadas en esta u otras Leyes, se tomará en consideración únicamente aquélla que comporte la mayor sanción.

5. Las cuantías de las multas serán revisadas y actualizadas periódicamente por el Gobierno mediante real decreto.

LEY 14/2007, de 3 de julio, de Investigación biomédica.

TÍTULO IV

Sobre la obtención y uso de células y tejidos de origen embrionario humano y de otras células semejantes

\section{CAPÍTULO I}

Sobre la utilización de ovocitos y preembriones

Artículo 33. Obtención de células de origen embrionario.

1. Se prohíbe la constitución de preembriones y embriones humanos exclusivamente con fines de experimentación.

2. Se permite la utilización de cualquier técnica de obtención de células troncales humanas con fines terapéuticos o de investigación, que no comporte la creación de un preembrión o de un embrión exclusivamente con este fin, en los términos definidos en esta Ley, incluida la activación de ovocitos mediante transferencia nuclear.

Artículo 35. Informe de la Comisión de Garantías para la Donación y la Utilización de Células y Tejidos Humanos.

1. Requerirán el informe previo favorable de la Comisión de Garantías para la Donación y Utilización de Células y Tejidos Humanos, los proyectos de investigación que versen en todo o en parte sobre las siguientes materias:

a) La investigación con preembriones humanos para la derivación de líneas celulares, para la investigación embriológica y para otros usos de investigación, excepto aquellos relacionados con el desarrollo y aplicación de las técnicas de reproducción asistida.

b) La investigación con células troncales embrionarias humanas.

c) La activación de ovocitos mediante transferencia nuclear para su uso con fines terapéuticos o de investigación. 
d) Cualquier otra técnica que, utilizando en todo o en parte muestras biológicas de origen humano, pueda dar lugar a la obtención de células troncales.

e) La investigación con células o tejidos embrionarios obtenidos por cualquiera de los procedimientos señalados en el artículo 33.2.

f) Cualquier otra línea de investigación que incluya material celular de origen embrionario humano u otro funcionalmente semejante.

g) La investigación con líneas de células troncales embrionarias que provengan de otro país, intracomunitario o extracomunitario. Dicho origen vendrá especificado en el proyecto presentado a informe.

LEY ORGÁNICA 15/2003, de 25 de noviembre, por la que se modifica la Ley Orgánica 10/1995, de 23 de noviembre, del Código Penal.

Quincuagésimo sexto. Se modifica el artículo 160, que queda redactado como sigue: «1. La utilización de la ingeniería genética para producir armas biológicas o exterminadoras de la especie humana, será castigada con la pena de prisión de tres a siete años e inhabilitación especial para empleo o cargo público, profesión u oficio por tiempo de siete a 10 años. 2. Serán castigados con la pena de prisión de uno a cinco años e inhabilitación especial para empleo o cargo público, profesión u oficio de seis a 10 años quienes fecunden óvulos humanos con cualquier fin distinto a la procreación humana.

3. Con la misma pena se castigará la creación de seres humanos idénticos por clonación u otros procedimientos dirigidos a la selección de la raza.»

\subsection{La legislación británica}

Human Fertilisation and Embryology Act 1990

\section{Offences}

41.-(1) A person who-

(a) contravenes section 3(2) or 4(1)(c) of this Act, or

(b) does anything which, by virtue of section 3(3) of this Act, cannot be authorised by a licence, is guilty of an offence and liable on conviction on indictment to imprisonment for a term not exceeding ten years or a fine or both.

(2) A person who-

(a) contravenes section 3(1) of this Act, otherwise than by doing something which, by virtue of section 3(3) of this Act, cannot be authorised by a licence,

(b) keeps or uses any gametes in contravention of section 4(1 )(a) or (b) of this Act,

(c) contravenes section 4(3) of this Act, or

(d) fails to comply with any directions given by virtue of section 24(7)(a) of this Act, is guilty of an offence.

(3) If a person-

(a) provides any information for the purposes of the grant of a licence, being information which is false or misleading in a material particular, and

(b) either he knows the information to be false or misleading in a material particular or he provides the information recklessly, he is guilty of an offence.

(4) A person guilty of an offence under subsection (2) or (3) above is liable- 
(a) on conviction on indictment, to imprisonment for a term not exceeding two years or a fine or both, and

(b) on summary conviction, to imprisonment for a term not exceeding six months or a fine not exceeding the statutory maximum or both.

Human Fertilisation and Embryology Act 2008

3 Prohibitions in connection with embryos

(1) Section 3 of the 1990 Act (prohibitions in connection with embryos) is amended as follows.

(2) For subsection (2) substitute-

"(2) No person shall place in a woman-

(a) an embryo other than a permitted embryo (as defined by section 3ZA), or

(b) any gametes other than permitted eggs or permitted sperm (as so defined)."

(3) In subsection (3) -

(a) at the end of paragraph (b), insert "or", and

(b) omit paragraph (d) and the word "or" immediately before it.

(4) In subsection (4), for "the day when the gametes are mixed" substitute "the day on which the process of creating the embryo began".

(5) After section 3 insert-

"3ZA Permitted eggs, permitted sperm and permitted embryos

(1) This section has effect for the interpretation of section 3(2).

(2) A permitted egg is one-

(a) which has been produced by or extracted from the ovaries of a woman, and

(b) whose nuclear or mitochondrial DNA has not been altered.

(3) Permitted sperm are sperm-

(a) which have been produced by or extracted from the testes of a man, and

(b) whose nuclear or mitochondrial DNA has not been altered.

(4) An embryo is a permitted embryo if-

(a) it has been created by the fertilisation of a permitted egg by permitted sperm,

(b) no nuclear or mitochondrial DNA of any cell of the embryo has been altered, and

(c) no cell has been added to it other than by division of the embryo's own cells.

(5) Regulations may provide that-

(a) an egg can be a permitted egg, or

(b) an embryo can be a permitted embryo, even though the egg or embryo has had applied to it in prescribed circumstances a prescribed process designed to prevent the transmission of serious mitochondrial disease.

(6) In this section-

(a) "woman" and "man" include respectively a girl and a boy (from birth), and

(b) "prescribed" means prescribed by regulations."

(6) The Human Reproductive Cloning Act 2001 (c. 23) (which is superseded by the preceding provisions of this section) ceases to have effect. 


\section{Referencias bibliográficas}

Alcaraz, E., Hugues, B. y Gómez, A. (2014): El español Jurídico, Barcelona, Editorial Ariel.

Belluscio, A. (1999): "La clonación humana frente al derecho", http://www.abeledoperrot.com/

Calise, S. (2011): "La clonación y sus metáforas. Sobre cómo el sistema jurídico argentino comprende la clonación humana", Discurso y Sociedad, 5, págs. 259-298.

Calise, S. (2014): "La clonación humana en los proyectos de ley de la Argentina: un análisis desde la lingüística sistémico-funcional”, $E L U A, 28$, págs. 57-86.

Calsamiglia, H. y Dijk, T. van. (2004): "Popularization discourse and knowledge about the genome", Discourse and Society. 15(4), págs. 369-389.

Ceccarelli, L. (2004): "Neither Confusing Cacophony Nor Culinary Complements A Case Study of Mixed Metaphors for Genomic Science", Written Communication, 21(1), págs. 92-105.

Ciuro Caldani, M.A. (2001): "Notas sobre el significado jurídico del lenguaje bioético", Bioética y Bioderecho, 2, págs., 73-76.

Condit, C. (1999): "How the public understands genetics: non-deterministic and non-discriminatory interpretations of the 'blue-print' metaphor", Public Understanding of Science. 8, págs. 169-180.

Condit, C. y Condit, D. (2001): "Blueprints and Recipes: Gendered Metaphors for Genetic Medicine" Journal of Medical Humanities, 22(1), págs. 29-39.

Eggins, S. (2004): An Introduction to Systemic Functional Linguistics, Nueva York, Continuum.

Eggins, S. y Martin, J.R. (1997): “Genres and Registers of Discourse". En Van Dijk, T. (Ed.). Discourse as Structure and Process. Discourse Studies: A Multidisciplinary Introduction Volume 1. Londres: Sage, pp. 230-256.

García, M.A. (2013): "El lenguaje jurídico escrito español en una perspectiva textual y oracional: patologías, buenas prácticas y versiones alternativas”, Linha d’Água, 26 (2), págs. 19-49.

Ghio, E. y Fernández, M. D. (2008): Lingüística sistémico funcional. Aplicaciones a la lengua española, Santa Fe, Universidad Nacional del Litoral, Waldhuter Editores.

González Salgado, J. (2009): "El lenguaje jurídico del siglo XXI", Themis Revista de Derecho, 57, págs. 235-245.

Halliday, M. A. K. (1990): Spoken and Written Language, Oxford, Oxford University Press.

Halliday, M. A. K. (1994): An Introduction to Functional Grammar (2 Ed.), Nueva York, Arnold.

Halliday, M. A. K. (2003): "Language and the Order of Nature", En On Language and Linguistics (Volume 3 in the Collected Works of M. A. K. Halliday), Londres y Nueva York, Continuum, págs. 116-138.

Halliday, M. A. K. (2004a). "On the Language of Physical Science", En The Language of Science (Volume 5 in the Collected Works of M. A. K. Halliday), Londres y Nueva York, Continuum, págs. 140-158.

Halliday, M. A. K. (2004b): "Things and Relations. Regrammaticizing Experience as Technical Knowledge", En The Language of Science (Volume 5 in the Collected Works of M. A. K. Halliday), Londres y Nueva York, Continuum, págs. 49-101.

Halliday, M. A. K. y Matthiessen, C. (2004): An Introduction to Functional Grammar ( $3^{\circ}$ Ed.), Londres, Arnold.

Hellsten, I. (2000): “Dolly: Scientific breakthrough or Frankenstein's monster? Journalistic and scientific metaphors of cloning", Metaphor and Symbol, 15(4), págs. 213-221.

Howe, N. (1983): "Further thoughts on clone", American Speech, 58(1), págs. 61-68.

Hunt Lazerson, B. (1982): "Born again clones”, American Speech, 57(4), págs. 264-269.

Journet, D. (2005): "Metaphor, Ambiguity, and Motive in Evolutionary Biology: W. D. Hamilton and the "Gene's Point of View"', Written Communication, 22(4), págs. 379-420.

Kemelmajer de Carlucci, A. (2001): "Determinación de la filiación del clonado", http://www.abeledoperrot.com/

Knudsen, S. (2005): "Communicating novel and conventional scientific metaphors: a study of the development of the metaphor of genetic code", Public Understanding of Science, 14, págs. 373-392. 
Liakopoulos, M. (2002): "Pandora's Box or panacea? Using metaphors to create the public representations of biotechnology", Public Understanding Of Science, 11, págs. 5-32.

Martí del Burgo y Marchán, Á. (2000): El lenguaje del Derecho", Barcelona, Bosch.

Messina de Estrella Gutiérrez, Graciela N. (1998): "Bioderecho", http://www.abeledoperrot.com/

Montemayor-Borsinger, A. (2007): "El análisis de la organización del discurso literario en español. Una propuesta desde la Lingüística Sistémico Funcional”, Co-herencia, 4 (7), págs. 133-153.

Montemayor-Borsinger, A. (2009): Tema: una perspectiva funcional de la organización del discurso, Buenos Aires, Eudeba.

Montemayor-Borsinger, A. (2011): “'Theme' and 'Subject' in Systemic Functional Linguistics: A Discussion of Thematic Status", Cadernos de Linguagem e Sociedade, 12 (1), págs. 66-77.

Mulkay, M. (1993): "Rhetorics of Hope and Fear in the Great Embryo Debate", Social Studies of Science, 23, págs. 721-742.

Mulkay, M. (1994a): "Science and Family in the Great Embryo Debate", Sociology, 28(3), págs. 699-715.

Mulkay, M. (1994b): "The Triumph of the Pre-Embryo: Interpretations of the Human Embryo in Parliamentary Debate over Embryo Research”, Social Studies of Science, 24, págs. 611-639.

Mulkay, M. (1995a): "Galileo and the Embryos: Religion and Science in Parliamentary Debate over Research on Human Embryos", Social Studies of Science, 25, págs. 499-532.

Mulkay, M. (1995b). "Parliamentary Ambivalence in Relation to Embryo Research", Social Studies of Science, 25, págs. 149.

Nerlich, B., Dingwall, R. y Clarke, D. (2002): "The book of life: how the completion of the Human Genome Project was revealed to the public", Health: An Interdisciplinary Journal for the Social Study of Health, Illness and Medicine, 6(4), págs. 445-469.

Nerlich, B. (2009): “'The post-antibiotic apocalypse' and the 'war on superbugs': catastrophe discourse in microbiology, its rhetorical form and political function", Public Understanding of Science, 18(5), págs. 574-590.-163.

Neves, M. (1994): A Constitucionalizaçao Simbólica, San Pablo, Editora Académica.

Parry, S. (2003): "The politics of cloning: mapping the rhetorical convergence of embryos and stem cells in parliamentary debates", New genetics and society, 22(2), págs. 145-168.

Pattinson, S. (2002): "Reproductive Cloning: Can Cloning Harm the Clone?", Medical Law Review, 10 (3), págs. 295-307.

Pramling, N. y Säljö, R. (2007): "Scientific Knowledge, Popularisation, and the Use of Metaphors: Modern genetics in popular science magazines", Scandinavian Journal of Educational Research, 51(3), págs. 275-295.

Prieto de Pedro, J. (1991): Lenguas, lenguaje y Derecho. Madrid, Civitas.

Prior, L. (2007): "Talking About the Gene for Cancer: A Study of Lay and Professional Knowledge of Cancer Genetics", Sociology. 41(6), págs. 985-1001.

Ratto, M. (2006): "Foundations and profiles: splicing metaphors in genetic databases and biobanks", Public Understanding of Science, 15, págs. 31-53.

Santiago Guervós, J. de (2001): "Lenguaje jurídico y norma”, En Bartol Hernández, J.A. et ali (Ed.): Nuevas aportaciones al estudio de la lengua española. Investigaciones filológicas, Salamanca, Luso-Española de Ediciones, pp. 287-298.

Temmerman, R. (2007): "Les métaphores dans les sciences de la vie et le situé socioculturel”, Cahier du Rifal, 26, págs. $72-82$.

Williams Camus, J. (2009): "Metaphors of cancer in scientific popularization articles in the British press", Discourse Studies, 11(4), págs. 465-495.

Williams, C., Kitzinger, J. y Henderson, L. (2003): "Envisaging the embryo in stem cell research: rhetorical strategies and media reporting of the ethical debates", Sociology of Health and Illness. 25(7), págs. 793-814. 
